\title{
Quasi-Decadal Variability of the Tropical Lower Stratosphere: The Role of Extratropical Wave Forcing
}

\author{
L. L. HoOD \\ Lunar and Planetary Laboratory, The University of Arizona, Tucson, Arizona \\ B. E. SOUKharev \\ Institut für Meteorologie, Freie Universität Berlin, Berlin, Germany
}

(Manuscript received 16 August 2002, in final form 24 April 2003)

\section{ABSTRACT}

\begin{abstract}
Column ozone and satellite-derived temperature records with lengths $>20 \mathrm{yr}$ are consistent with the existence of a long-term, quasi-decadal oscillation (QDO) of the tropical lower stratosphere. Using a one-dimensional model for the quasi-biennial oscillation (QBO) of ozone and temperature, it is found that decadal variability of the QBO can account for, at most, only a minor fraction of the tropical lower-stratospheric QDO. One additional source of long-term variability in the Tropics is extratropical wave forcing, which is an important driver of the Brewer-Dobson circulation. To investigate possible long-term variability of extratropical wave forcing, daily and monthly mean meridional eddy heat fluxes are calculated at a series of lower-stratospheric pressure levels over a 23-yr period using National Centers for Environmental Prediction (NCEP) reanalysis data. A decadal variation of the low-pass-filtered extratropical eddy heat flux is present in the Northern Hemisphere with an amplitude that increases with increasing altitude. In the extratropical Southern Hemisphere, a decadal variation is also present but is less regular, possibly owing to reduced radiosonde data coverage. A simplified model of the contribution of extratropical wave forcing to long-term variations in tropical lower-stratospheric ozone and temperature is then formulated based on the ozone chemical continuity and thermodynamic energy equations. Using this model together with empirically derived regression relationships between short-term changes in extratropical eddy heat flux and tendencies in both tropical column ozone and lower-stratospheric temperature, it is found that decadal variations of extratropical wave forcing in both hemispheres may be sufficient to explain much of the amplitude and the phase of the observed QDO of the tropical lower stratosphere.
\end{abstract}

\section{Introduction}

A more complete understanding of natural sources of long-term variability in the atmosphere is needed for more accurate model simulations of both natural and anthropogenic climate change (WMO 1999; Houghton et al. 2001). Possible sources of natural interannual atmospheric variability include: 1) interannual changes in the internal dynamics of the atmosphere-ocean system, such as those associated with the equatorial quasi-biennial wind oscillation (QBO) (Baldwin et al. 2001) and the El Niño-Southern Oscillation (ENSO) (Trenberth and Hoar 1997); 2) changes in the abundances of volcanically injected aerosol and trace gases (Robock 2000); and 3) long-term ( $\geq 11$-yr) changes in solar ultraviolet (UV) spectral irradiance (e.g., Hood 2003). The tropical lower stratosphere is of particular interest as a site for studying long-term variability in the atmosphere

Corresponding author address: L. L. Hood, Space Sciences Building, The University of Arizona, 1629 E. University Blvd., Tucson, AZ 85721-0092.

E-mail: lon@lpl.arizona.edu because (a) it is above the tropopause and is therefore relatively free of short-term fluctuations driven by moist convection and baroclinic instabilities; (b) it is less disturbed by seasonal and short-term variations driven dynamically in the extratropical winter stratosphere; and (c) it is the principal zone for the exchange of radiatively important trace species (e.g., ozone, water vapor) between the troposphere and the stratosphere (for a review, see Holton et al. 1995).

It has been known for more than $50 \mathrm{yr}$ that a mean meridional circulation exists in the stratosphere characterized by ascent in the Tropics and descent in the extratropics (Brewer 1949). This "Brewer-Dobson" circulation is driven by a combination of the seasonal cycle in diabatic heating and by the absorption and dissipation of extratropical Rossby and gravity waves originating in the troposphere, which decelerate the zonal wind and induce a poleward flow (Garcia 1987; Holton 1990; Dunkerton 1991; Haynes et al. 1991; Plumb and Eluskiewicz 1999; Norton 2001).

On short timescales, such as that associated with major warmings of the polar winter stratosphere, tropical 
ozone and temperature variations correlate inversely with those at high latitudes (Fritz and Soules 1972; Chandra 1986). Consistently, the rate of planetary wave absorption at northern middle to high latitudes, has been shown to correlate inversely with temporal tendencies in tropical column ozone (Randel 1993). A recent analysis by Randel et al. (2002a) has further quantified the influence of extratropical wave forcing on tropical upwelling for timescales ranging from weekly to seasonal. These results support the view that an important part of the tropical ascent branch of the Brewer-Dobson circulation is driven by extratropical wave forcing (see also Holton et al. 1995).

Previous studies of interannual variability in the tropical lower stratosphere have focused especially on the effects of the QBO, ENSO, volcanic eruptions, and on the estimation of long-term trends (e.g., Krishna Murthy et al. 1986; Labitzke and McCormick 1992; Randel et al. 2000). However, a number of statistical studies have also indicated that a quasi-decadal variation is present in the tropical lower stratosphere (e.g., Chandra 1991; Hood 1997; Camp et al. 2003). The amplitude is largest near $30^{\circ}$ latitude in both hemispheres but is statistically significant throughout the Tropics and subtropics (McCormack et al. 1997). This decadal variation is approximately in phase with the 11-yr solar activity cycle; however, the short lengths of available records $(<4$ decades) and the absence of a detailed physical model connecting solar variability with the tropical lower stratosphere have inhibited general acceptance of a solar origin. For the sake of brevity, in the remainder of this paper, we will refer to the decadal variation of the tropical lower stratosphere as the "quasi-decadal oscillation" (QDO). However it is emphasized that the lengths of available data records are still insufficient to determine whether the term oscillation is appropriate.

In this paper, we investigate further the origin of the quasi-decadal component of long-term variability in the tropical lower stratosphere. In section 2, observational evidence for this component is first briefly summarized using two independent and relatively reliable satellitebased data records. In section 3, a modified version of a one-dimensional perturbation model originally developed by Hasebe (1994) and based on an earlier formulation by Ling and London (1986) is applied to simulate approximately the QBO component of total ozone and lower stratospheric temperature variability at the equator. We specifically investigate whether decadal variations of the QBO zonal wind field and its associated mean meridional circulation in the Tropics and subtropics can explain the lower-stratospheric quasi-decadal variation. In section 4 , we investigate whether longterm variations in the extratropical wave forcing component of tropical upwelling could be responsible for the observed decadal variations of the tropical lower stratosphere. As a measure of the amount of extratropical wave forcing, values of the meridional eddy heat flux, $\overline{v^{\prime} T^{\prime}}$, in the lower stratosphere are employed. Con- clusions and possible implications are discussed in section 5 .

\section{Observational evidence for decadal variability in the tropical lower stratosphere}

Because of the sparsity of radiosonde data in the Tropics, any observational study of multidecadal variability in the equatorial lower stratosphere must consider only carefully intercalibrated data records. We consider here two such records derived directly from global satellite measurements begun in 1979: 1) The combined Total Ozone Mapping Spectrometer (TOMS) and Solar Backscattered Ultraviolet (SBUV) record for the ozone column (Stolarski et al. 2000; McPeters et al. 1996); and 2) the weighted mean $(\sim 40-120 \mathrm{hPa})$ lower-stratospheric temperature record derived from radiances obtained using channel 4 of the Microwave Sounding Units (MSU4) on the operational satellites of the National Oceanic and Atmospheric Administration (Spencer and Christy 1993; Spencer et al. 1990). All data were obtained electronically from the internet web sites: http://code916.gsfc.nasa.gov/Data_services/merged and http://vortex.nsstc.uah.edu/data/msu/.

Plotted in Fig. 1 are deviations from long-term (19792000) monthly means of zonally averaged TOMS/ SBUV total ozone ( $\left.1 \mathrm{DU}=10 \mu \mathrm{m} \mathrm{O}_{3} \mathrm{STP}\right)$ and MSU4 temperature data, averaged over the Tropics $\left(20^{\circ} \mathrm{S}-\right.$ $20^{\circ} \mathrm{N}$ ) for the period $1979-2000$. In the case of the ozone data, a QDO is evident with maxima at approximately 1980, 1990, and 2000. In the case of the MSU4 temperature data, significant temperature increases are recorded following the El Chichon (C) and Pinatubo (P) volcanic aerosol injection events (e.g., Labitzke and McCormick 1992). However, a careful examination of the time series outside of these two periods indicates a longer-term, decadal variation that correlates approximately with the total ozone record. In particular, temperature increases occurring between 1985 and 1990 and also between 1995 and 2000 are not easily explained in terms of aerosol heating effects. Application of a multiple regression statistical model (with seasonal, QBO, solar cycle, stratospheric aerosol, and trend terms) to the tropical mean MSU4 time series yields a significant solar regression coefficient with a peak-to-peak amplitude of $0.70 \pm 0.18 \mathrm{~K}$. Previous analyses of Nimbus-7 SBUV ozone profile data have shown that most ( $\sim 85 \%)$ of the solar-correlated decadal column ozone variation occurs in the lower stratosphere below the $\sim 30$-hPa level (see Table 1 of Hood 1997).

Figures 2 and 3 show deviations from long-term (1979-2000) monthly means of the TOMS/SBUV total ozone and MSU4 temperature data averaged within three $10^{\circ}$ latitude bands in the Tropics. Separating the data in this manner reveals a strong influence of the QBO on equatorial column ozone and, to a lesser extent, on MSU4 temperature. Because the QBO zonal wind field is in approximate thermal wind balance (e.g., 


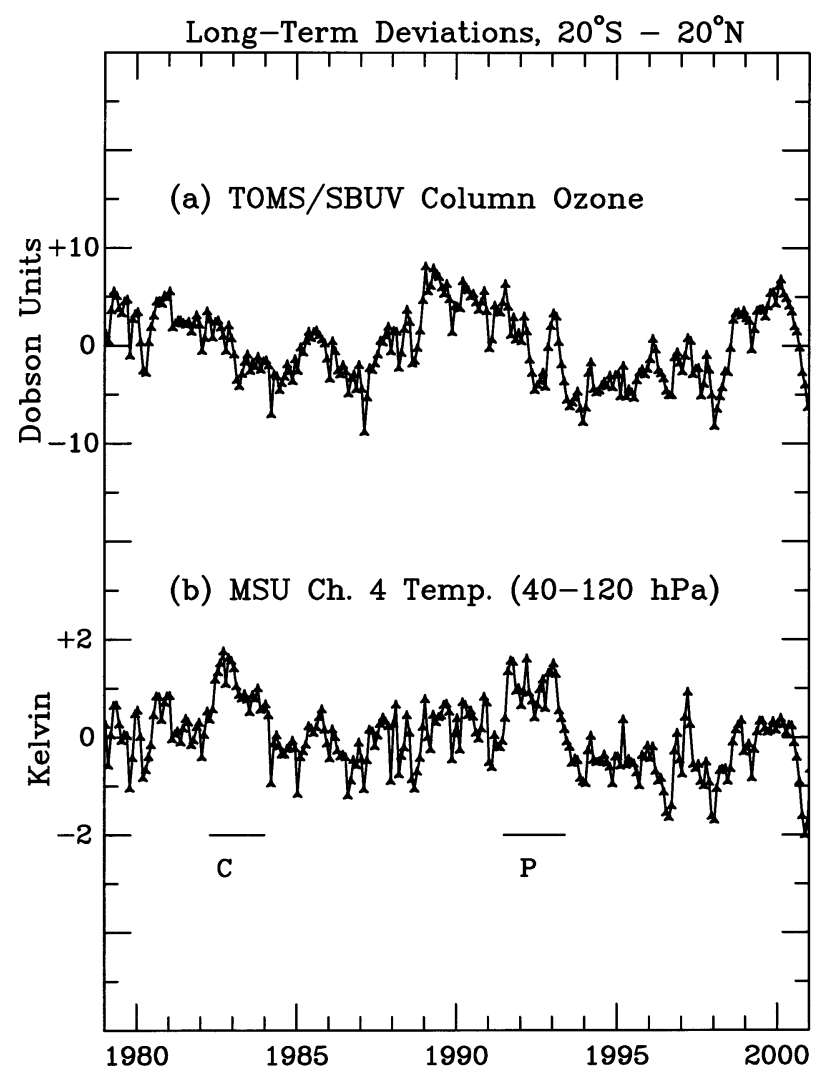

FIG. 1. Deviations from long-term monthly means of (a) zonally averaged TOMS/SBUV total column ozone and (b) MSU channel 4 temperature data, averaged over the $20^{\circ} \mathrm{S}$ to $20^{\circ} \mathrm{N}$ latitude range. Twoyear periods following the El Chichon $(\mathrm{C})$ and Pinatubo $(\mathrm{P})$ volcanic eruptions are also indicated.

Plumb and Bell 1982), periods of maximum westerly vertical shear are associated with an induced meridional circulation anomaly characterized by adiabatic descent near the equator and ascent in the subtropics. Equatorial descent in the presence of a positive vertical gradient in ozone mixing ratio and positive static stability results in positive ozone and temperature anomalies. During periods of maximum easterly vertical shear, the opposite is true. In Figs. 2 and 3, the upper and lower plots (at $10^{\circ} \mathrm{N}$ and $10^{\circ} \mathrm{S}$ ) are located near nodes in the QBOinduced anomalous meridional circulation and so exhibit a weaker QBO influence. The greater amplitude of the QBO component of equatorial column ozone as compared to that of MSU4 temperature is mainly a consequence of the location of maximum QBO vertical wind shear (and maximum induced vertical velocities) above the 50-hPa level.

\section{The QBO component of decadal variability in the tropical lower stratosphere}

Statistical studies have indicated significant decadal variability of the QBO zonal wind field (Salby and Callaghan 2000; Soukharev and Hood 2001). In this sec-

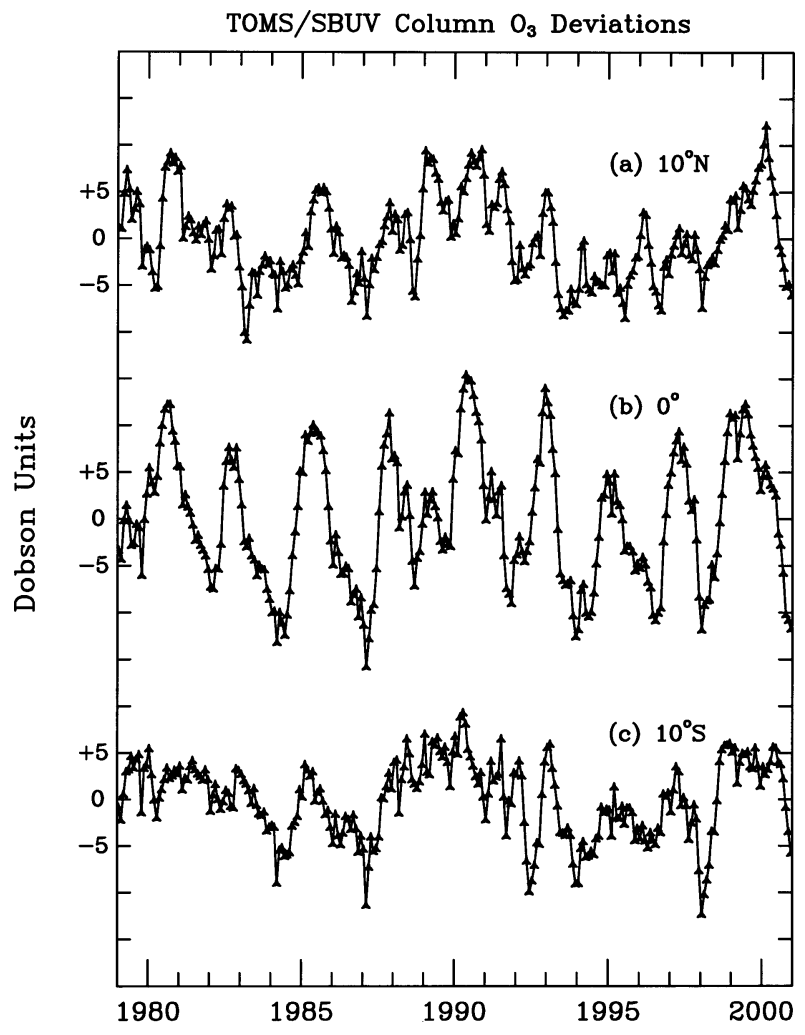

FIG. 2. Same data as in Fig. 1a but for TOMS/SBUV total column ozone within $10^{\circ}$ latitude bands centered on (a) $10^{\circ} \mathrm{N}$, (b) $0^{\circ}$, and (c) $10^{\circ} \mathrm{S}$

tion, we consider a simplified, one-dimensional mechanistic model that uses the observed equatorial zonal winds as input to simulate the time evolution of the ozone QBO (Hasebe 1994; see also Ling and London 1986). The purpose is to carry out an initial investigation of whether decadal variations of the QBO zonal wind field could be partly or entirely responsible for the QDO of tropical mean ozone and temperature shown in Fig. 1. A more complete investigation using a detailed twodimensional model of the ozone and temperature QBO is desirable but is deferred to future work.

The model is based on perturbation equations describing the thermal wind relationship, conservation of thermodynamic energy, and ozone continuity:

$$
\begin{gathered}
\frac{\partial \theta_{B}}{\partial y}=-\frac{2 \Omega y}{a} \frac{\partial u_{B}}{\partial z}, \\
\frac{\partial \theta_{B}}{\partial t}+w_{B} N^{2}=-h \theta_{B}+S \chi_{B} \\
\frac{\partial \chi_{B}}{\partial t}+w_{B} \chi_{0 z}=\Gamma \chi_{B}+\alpha \theta_{B},
\end{gathered}
$$

where $\theta_{B}$ is the $\mathrm{QBO}$ component of zonal mean buoyancy acceleration, $u_{B}$ is the QBO component of zonal mean zonal wind, $w_{B}$ is the QBO component of Lagrangian mean vertical velocity, $\chi_{B}$ is the QBO com- 


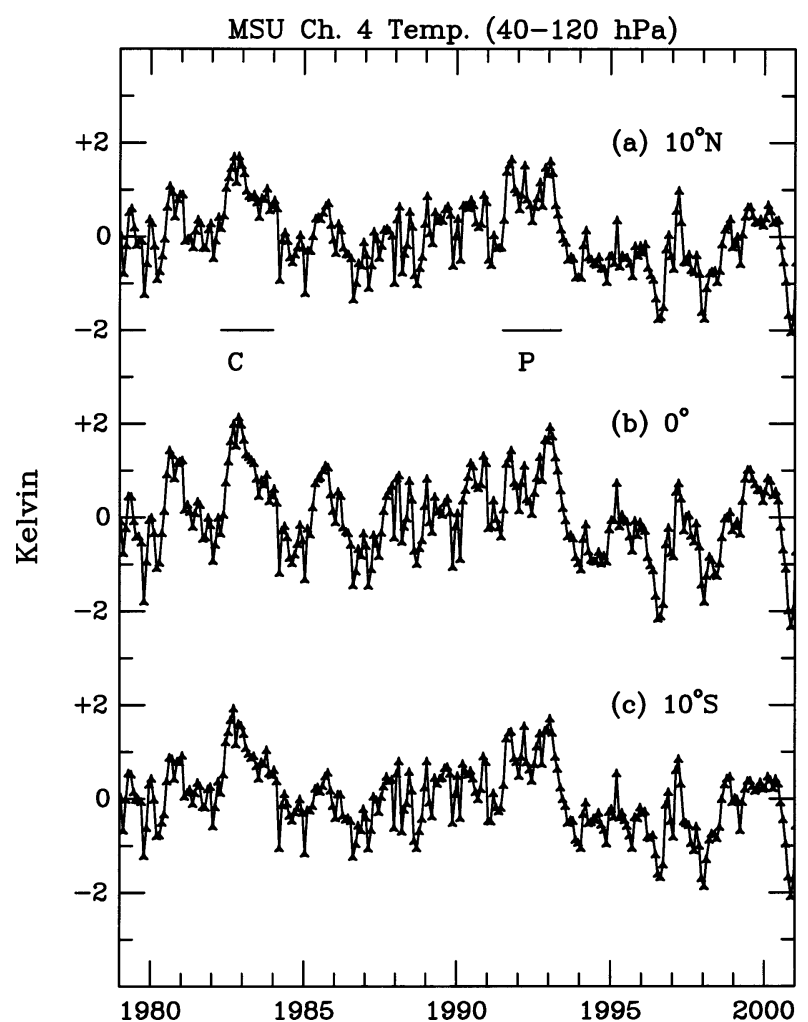

FIG. 3. Same data as in Fig. $1 \mathrm{~b}$ but for MSU channel 4 temperature data within $10^{\circ}$ latitude bands centered on (a) $10^{\circ} \mathrm{N}$, (b) $0^{\circ}$, and (c) $10^{\circ} \mathrm{S}$.

ponent of the ozone mixing ratio, $y$ and $z$ are meridional and vertical coordinates, $\Omega$ is the earth rotation angular frequency, $a$ is the earth's radius, $N$ is the buoyancy frequency, $h$ is the Newtonian cooling coefficient, $\chi_{0 z}$ is the vertical gradient of the basic-state ozone volume mixing ratio, $S$ is the perturbation ozone heating rate, $\Gamma$ is the inverse of the ozone photochemical lifetime, and $\alpha$ is the photochemical sensitivity of ozone to temperature changes. Here $\theta_{B}$ is related to temperature $T$ by $\theta_{B}=R T / H$, where $R$ is the dry air gas constant and $H$ is the scale height. Although Eqs. (1)-(3) are adopted here to be consistent with the Hasebe (1994) formulation, it should be noted that Eq. (1) is not strictly valid at the equator [see Eq. (8.2.2) of Andrews et al. 1987].

Assuming a simple meridional decay of zonal wind and temperature with distance $y$ from the equator of the form $u_{B}=u_{0}(z, t) \exp \left(-y^{2} / k^{2}\right)$ and $\theta_{B}=\theta_{0}(z, t)$ $\exp \left(-y^{2} / k^{2}\right)$, and further neglecting the first term on the left side of (2), one can obtain an analytic solution for the QBO ozone mixing ratio component, $\chi_{B}$, of the form (Hasebe 1994):

$$
\begin{aligned}
\chi_{B}(t)= & (h \mu+\alpha) \int_{0}^{t}[\exp -(S \mu-\Gamma) \tau] \theta_{B}(t-\tau) d \tau \\
& +\chi_{B}(0) \exp -(S \mu-\Gamma) t
\end{aligned}
$$

where $\tau$ is a variable of integration, $\mu$ is the ratio of the

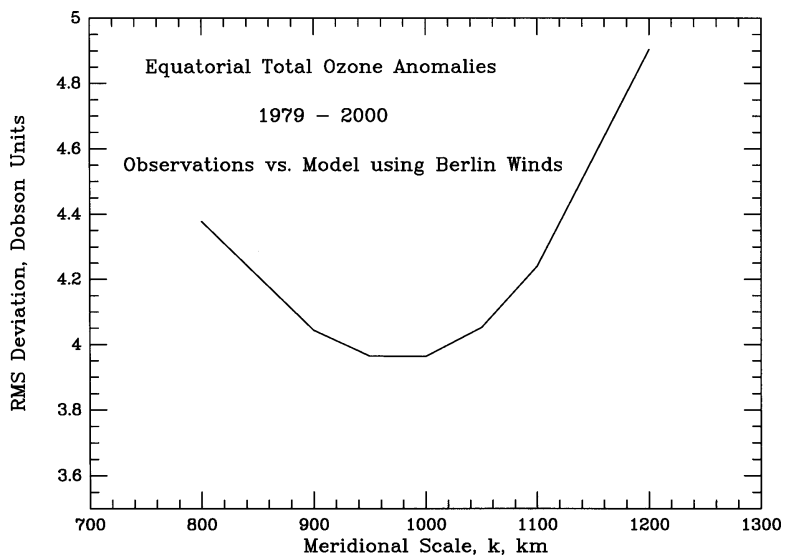

FIG. 4. Rms deviation between the model described in the text and the equatorial TOMS/SBUV deviations shown in Fig. 2 plotted as a function of the assumed meridional scale of the QBO, $k$.

vertical gradient of the basic state ozone volume mixing ratio to the buoyancy frequency squared, and

$$
\theta_{B}(t)=\frac{k^{2} \Omega}{a} \frac{\partial u_{B}(t)}{\partial z}
$$

Using equatorial zonal winds from Berlin analyses (B. Naujokat 2001, personal communication) and values of constant parameters taken from Ling and London (1986) as tabulated by Hasebe (1994), (4) was evaluated at a series of pressure levels $(10,15,20,30,40,50,70 \mathrm{hPa})$ as a function of time. These were then converted to QBO ozone concentrations using climatological number densities; the QBO total ozone deviations for each month were estimated by summing these concentrations over altitude. Since the goal of this analysis is to investigate whether decadal variations in the $\mathrm{QBO}$ may explain the observed QDO of ozone and temperature, we did not filter out long-term variations in the zonal wind field by subtracting 27 -month running means, as was done by Hasebe (1994). The meridional scale $k$ was treated as a free parameter and was determined via a minimum variance fit of the model total ozone deviations to the observed deviations. As shown in Fig. 4, this procedure yields a preferred meridional scale of $k$ $\simeq 1000 \mathrm{~km}$, the same value adopted by Hasebe (1994).

Figure 5a compares the observed column ozone deviations (the same as plotted in the center panel of Fig. 2 ) to the Hasebe model data for $k=1000 \mathrm{~km}$. Overall, the model data track the observations reasonably well and do exhibit some decadal variation. For example, the model ozone minima are less negative near 1990, as is also true for the data. This reflects a tendency for easterly equatorial wind maxima near the $50-\mathrm{hPa}$ level to vary in amplitude on a decadal timescale (Salby and Callaghan 2000; Soukharev and Hood 2001). However, significant differences still exist. As shown in Fig. 5b, the model residuals (observed data minus model data) still exhibit a significant QDO with a peak-to-peak amplitude of several percent. As shown in Fig. 5c, the 


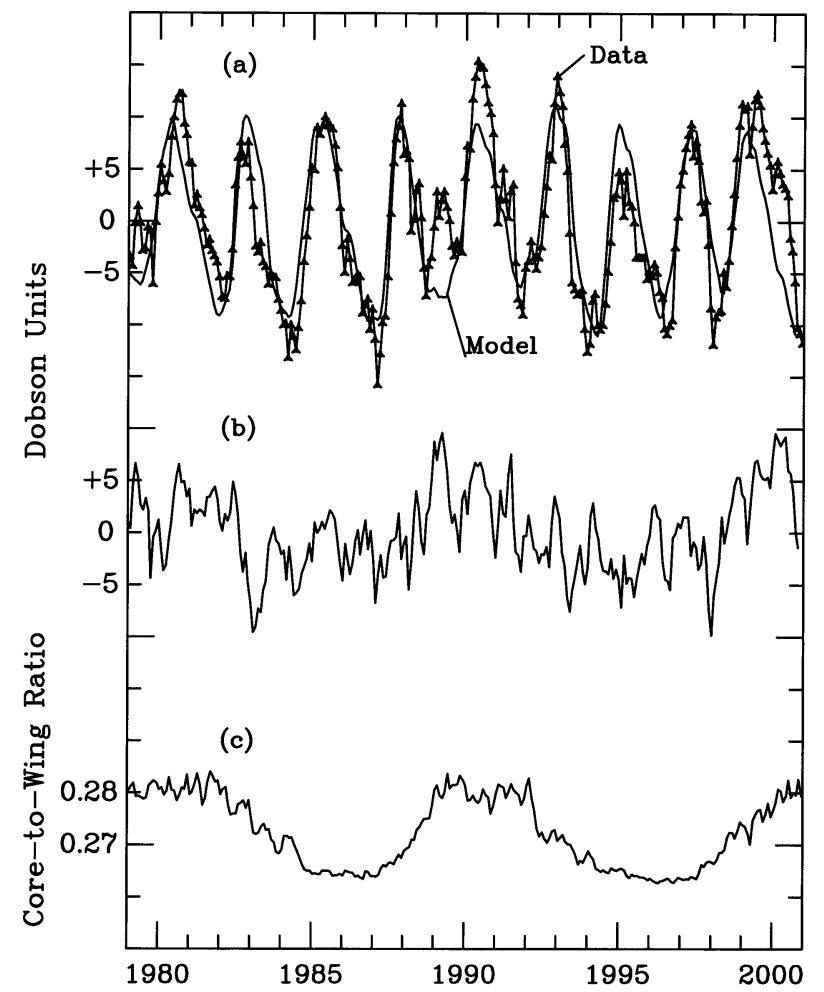

FIG. 5. Results of applying the Hasebe (1994) one-dimensional QBO model to the equatorial ozone data shown in Fig. 2 (center). (a) Comparison of the model (for $k=1000 \mathrm{~km}$ ) to the ozone data; (b) residual ozone time series (data minus model); (c) Mg II solar UV index (see the text).

residuals with maxima at $\sim 1980, \sim 1990$, and $\sim 2000$ correlate approximately with the solar Mg II core-towing ratio, a close proxy for solar UV variations at wavelengths near $200 \mathrm{~nm}$ (Heath and Schlesinger 1986). While the solar flux explains only $5.6 \%$ of the variance of the observed column ozone deviations $(\mathrm{R}=0.24)$, it explains $28 \%$ of the variance of the ozone residuals $(\mathrm{R}=0.53)$. However, the time record is too short to prove statistically a causal relationship between the two variables.

The solar Mg II ratios shown in Fig. 5c are estimated from a combination of Nimbus-7 SBUV data for 197993 (available online at http://www.sec.noaa.gov/) and National Aeronautics and Space Administration (NASA) Upper Atmosphere Research Satellite (UARS)/ Solar Ultraviolet Spectral Irradiance Monitor (SUSIM) data for 1991 to the present (available online at http:// wwwsolar.nrl.navy.mil/susim_uars.html). The combined series is normalized to the Nimbus-7 series using the mean difference between the two series calculated in the region of overlap.

Using Eq. (5) and the relationship $\theta_{B}=R T / H$, one may also calculate a model QBO temperature component for comparison to the observed equatorial temperature deviations in the center panel of Fig. 3. As shown in Fig. 6, a minimum rms deviation of the model QBO

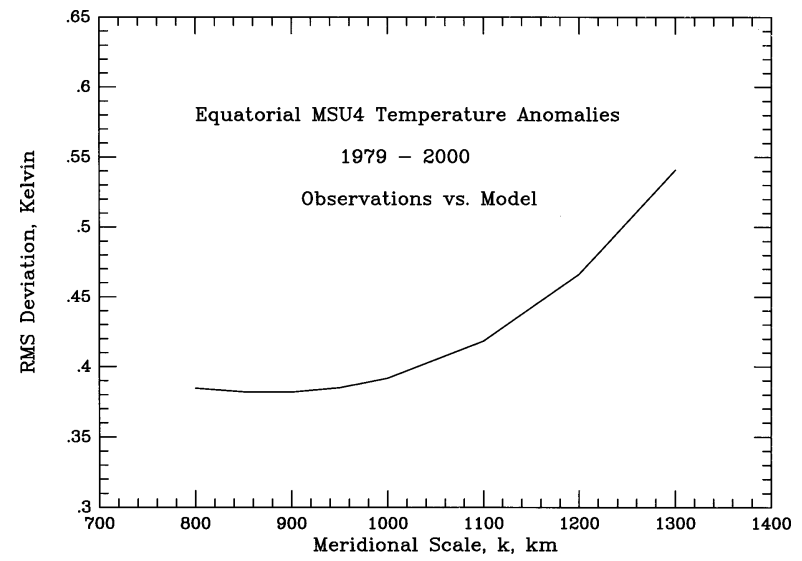

FIG. 6. Same format as in Fig. 4 but for the equatorial MSU channel 4 deviations shown in the center panel of Fig. 3.

temperature from the observed equatorial MSU4 temperature is obtained for a meridional scale $k \simeq 900 \mathrm{~km}$. Figure 7a compares the observed MSU4 temperature deviations to the model QBO deviations. It is seen that the QBO component explains only a small fraction of the total variance $(26 \% ; \mathrm{R}=0.51)$, while the solar flux explains even less $(6.8 \% ; \mathrm{R}=0.26)$. The small amplitude of the QBO temperature component in the MSU4 pressure range $(\sim 40-120 \mathrm{hPa})$ is a consequence of the

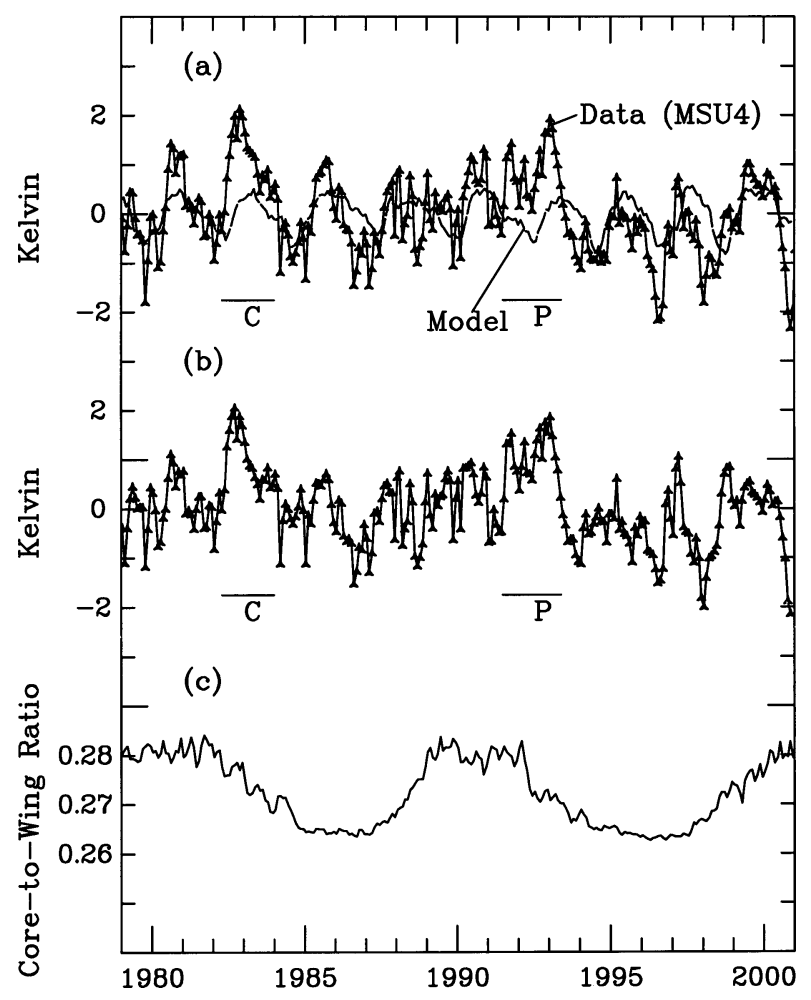

FIG. 7. Results of applying Eq. (5) to the equatorial MSU channel 4 temperature deviations shown in Fig. 3. (a) Comparison of the model (for $k=900 \mathrm{~km}$ ) to the temperature data; (b) residual temperature time series (data minus model); (c) Mg II solar UV index. 


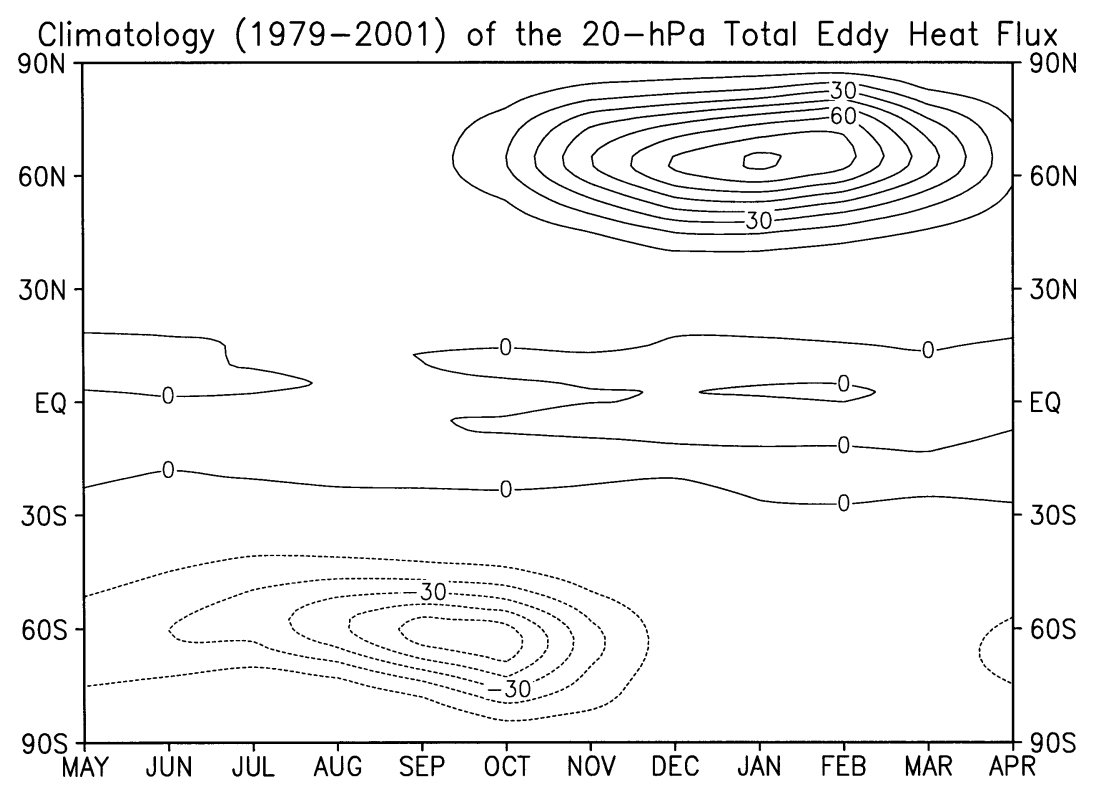

FIG. 8. Climatological mean of the meridional eddy heat flux $\overline{v^{\prime} T^{\prime}}$ as calculated using monthly averages of daily NCEP data for the 1979-2001 period.

weaker QBO vertical wind anomaly in this pressure range in the Tropics, as noted in section 2. Subtracting the model QBO temperature component from the observed temperature time series yields the residual MSU4 temperature time series shown in Fig. 7b. A remaining QDO is evident in the residuals that correlates weakly with the solar $\mathrm{Mg}$ II index $(\mathrm{R}=0.29 ; 8.6 \%$ of variance explained).

We emphasize that the results illustrated in Figs. 5 and 7 represent only an initial, first-order investigation of whether decadal variations in the QBO wind fields can explain the observed ozone and temperature QDO in the tropical lower stratosphere. The one-dimensional model considered here is simplified and incomplete in many respects. As noted earlier, the adopted form of the thermal wind equation is not strictly correct at the equator. Also, detailed analyses of the ozone QBO vertical structure (Chipperfield et al. 1994; Randel and Wu 1996) indicate a double-peaked structure at the equator, with the upper-level maximum due to $\mathrm{NO}_{x}$ chemical effects (which contribute about one-third of the column ozone signal). The idealized parameterizations in the Hasebe (1994) model do not capture this behavior in any detail. Thus, a complete investigation of QBO influences on ozone and temperature decadal variability in the tropical lower stratosphere will require future applications of more accurate two-dimensional models of the ozone QBO (e.g., McCormack and Siskind 2003).

\section{Extratropical wave forcing of decadal variability in the tropical lower stratosphere}

As discussed in the introduction, the tropical ascending branch of the meridional (Brewer-Dobson) circu- lation is driven by several competing processes including extratropical wave forcing. Differences in the rate of ascent will result in differences in lower-stratospheric ozone concentrations and adiabatic temperature differences. We therefore investigate in this section whether long-term variations in extratropical wave forcing may be sufficient to explain the decadal variability evident in Fig. 1. Further motivation for investigating this mechanism comes from a number of recent studies showing that variations in planetary wave activity entering the stratosphere (e.g., the vertical component of the Eliassen-Palm or EP flux, $F_{z}$ ) correlate significantly with column ozone changes and polar stratospheric temperatures on interannual timescales (Fusco and Salby 1999; Newman et al. 2001; Randel et al. 2002b). The EP flux divergence (sometimes called "wave driving") is a measure of the net force per unit mass on the zonal mean flow. Deceleration (acceleration) of the extratropical flow accelerates (decelerates) the meridional (BrewerDobson) circulation.

Following other authors, in this paper we represent the extratropical wave driving by the zonally averaged meridional eddy heat flux, $\overline{v^{\prime} T^{\prime}}$, which is approximately proportional to $F_{z}$. Figure 8 shows the climatological mean of the eddy heat flux at $20 \mathrm{hPa}$ based on National Centers for Environmental Prediction (NCEP) data for a 23 -yr period (Kalnay et al. 1996). At this level in the lower stratosphere, heat fluxes (and wave driving) are negligible in the summer in both hemispheres when planetary-scale waves are trapped by stratospheric easterlies (Charney and Drazin 1961). Maximum values are seen in January in the Northern Hemisphere (NH) and in September-October in the Southern Hemisphere (SH); amplitudes are largest in the $\mathrm{NH}(\sim 80$ vs $\sim 50 \mathrm{~K}$ 
$\left.\mathrm{m} \mathrm{s}^{-1}\right)$. Below, we will use values of $\overline{v^{\prime} T^{\prime}}$ at $60^{\circ} \mathrm{N}$ and $60^{\circ} \mathrm{S}$ (i.e., near latitudes where maxima are reached) as a measure of extratropical wave forcing in each hemisphere.

In order to derive an approximate relationship between extratropical wave forcing and ozone tendencies in the tropical lower stratosphere, it is useful to consider first the ozone continuity equation in the transformed Eulerian-mean (TEM) formulation (Andrews et al. 1987; Randel et al. 2002b),

$$
\frac{\partial \bar{\chi}}{\partial t}=-\bar{v}^{*} \bar{\chi}_{y}-\bar{w}^{*} \bar{\chi}_{z}+\nabla \cdot \mathbf{M}+\bar{S},
$$

where $\bar{\chi}$ is zonal mean ozone mixing ratio, $\overline{v^{*}}$ and $\overline{w^{*}}$ are mean meridional and vertical velocities, respectively, $\boldsymbol{\nabla} \cdot \mathbf{M}$ is the ozone tendency resulting from eddy transport, and $\bar{S}$ represents all chemical sources and sinks. Although all of the terms on the right side of (6) are important in general, the vertical transport term $\left(-\overline{w^{*}} \bar{\chi}_{z}\right)$ can apparently be dominant over horizontal and eddy transport in the tropical lower stratosphere on certain timescales. If the odd oxygen chemical lifetime is $\tau_{c}$, (6) may be written in a simplified, first-order form as

$$
\frac{\partial \bar{\chi}}{\partial t} \simeq-\overline{w^{*}} \bar{\chi}_{z}-\frac{\left(\bar{\chi}-\bar{\chi}_{\mathrm{eq}}\right)}{\tau_{c}},
$$

where $\bar{\chi}_{\text {eq }}$ is the chemical equilibrium value for $\bar{\chi}$. A typical value for $\tau_{c}$ is $\sim 6$ months in the lower stratosphere (e.g., Brasseur and Solomon 1984).

For the special case of extratropical wave absorption events occurring on short timescales (e.g., those associated with polar stratospheric sudden warming events), the chemical term on the right side of (7) can be approximately neglected. For these events, $\overline{w^{*}}$ in the Tropics is approximately proportional to $F_{z}$ in the extratropics and (7) may be written in the form:

$$
\frac{\partial \bar{\chi}}{\partial t} \propto-F_{z} \bar{\chi}_{z}
$$

Since $\bar{\chi}_{z}$ is positive in the lower stratosphere, we expect on the basis of (8) an inverse correlation between tropical ozone tendencies and extratropical wave driving as estimated by $F_{z}$. As first shown by Randel (1993), this inverse correlation is observed for short-term events during the northern winter when planetary waves in that hemisphere can propagate into the stratosphere.

It is also of interest to consider the expected relationship between tropical lower stratospheric temperature tendencies and extratropical wave forcing. In general, the TEM thermodynamic energy equation may be written as

$$
\frac{\partial \bar{T}}{\partial t}+\frac{\bar{v}^{*}}{a} \frac{\partial \bar{T}}{\partial \phi}+\bar{w}^{*}\left(\frac{H N^{2}}{R}\right)=\bar{Q},
$$

where $\bar{T}$ is zonal mean temperature, $\phi$ is latitude, and

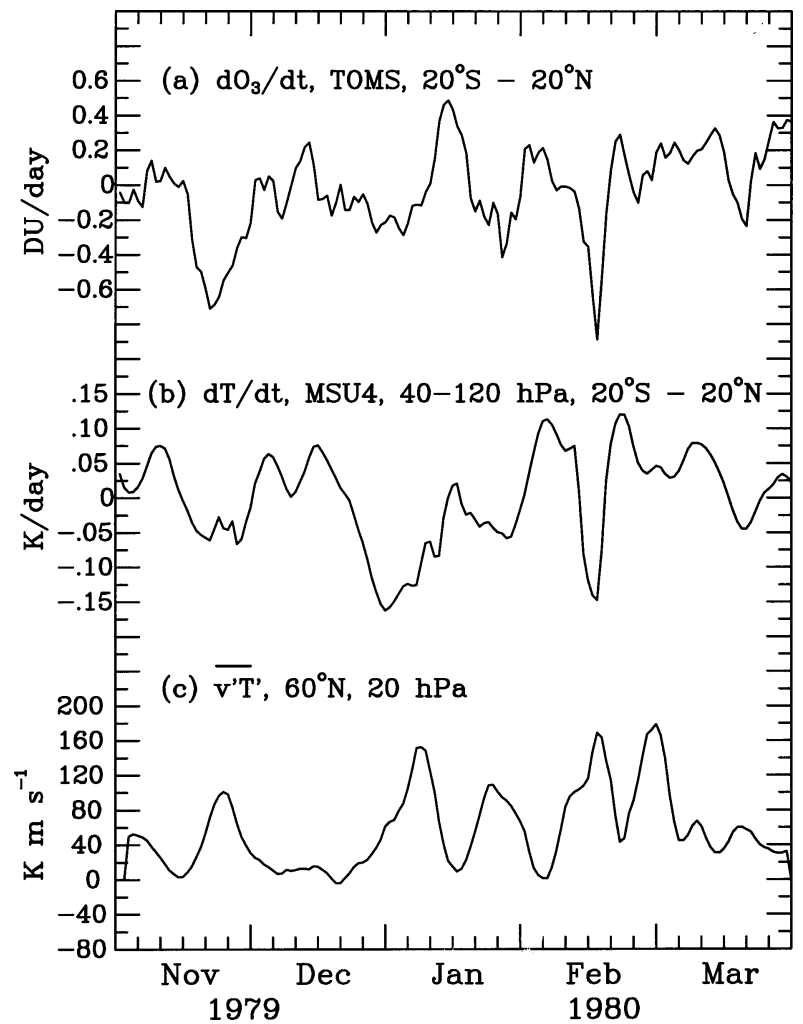

FIG. 9. (a) The time derivative of the 5-day running mean TOMS ozone time series averaged over the $20^{\circ} \mathrm{S}-20^{\circ} \mathrm{N}$ zone for a 5 -month period in late 1979 and early 1980. (b) The same quantity for MSU channel 4 temperature data. (c) The zonally averaged meridional eddy heat flux at $60^{\circ} \mathrm{N}, 20 \mathrm{hPa}$ as calculated from NCEP data.

$\bar{Q}$ is the zonal mean diabatic heating rate. Neglecting heat transport by meridional winds compared to vertical transport and neglecting short-wave heating compared to long-wave cooling, (9) may be written in the simplified form (e.g., Randel et al. 2002a).

$$
\frac{\partial \bar{T}}{\partial t} \simeq-\bar{w}^{*}\left(\frac{H N^{2}}{R}\right)-\left(\frac{\bar{T}-\bar{T}_{\mathrm{eq}}}{\tau_{r}}\right),
$$

where a Newtonian cooling approximation has been assumed with equilibrium temperature $\bar{T}_{\mathrm{eq}}$ and radiative lifetime $\tau_{r}$. In the lower stratosphere, $\tau_{r} \simeq 30-100$ days. The radiative term on the right side of (10) is therefore small for short-term wave absorption events. In the latter case, one obtains

$$
\frac{\partial \bar{T}}{\partial t} \propto-F_{z}\left(\frac{H N^{2}}{R}\right),
$$

where we have again assumed that $\overline{w^{*}}$ in the Tropics is approximately proportional to extratropical $F_{z}$. This equation has the same form as (8). Therefore, it is expected that both ozone and temperature in the tropical lower stratosphere will respond similarly to short-term changes in extratropical wave forcing.

In Figs. 9 and 10, examples of correlated fluctuations 


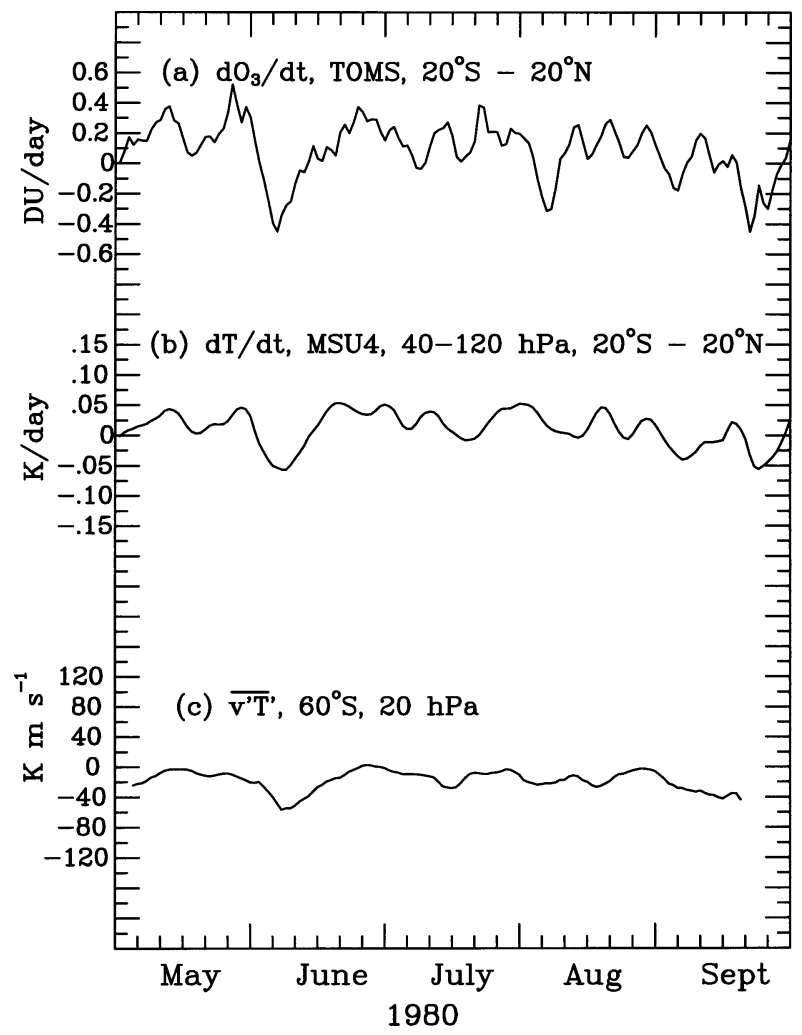

FIG. 10. Same format as Fig. 9 but for the period May-September 1980. (c) The zonally averaged meridional eddy heat flux at $60^{\circ} \mathrm{S}, 20$ $\mathrm{hPa}$ as calculated from the NCEP data.

in tropical column ozone tendencies, tropical MSU4 temperature tendencies, and extratropical wave forcing $\overline{v^{\prime} T^{\prime}}$ at $\left(20 \mathrm{hPa}, 60^{\circ}\right.$ latitude) are shown for both hemispheres. In Fig. 9, comparisons are made with $\overline{v^{\prime} T^{\prime}}$ at $60^{\circ} \mathrm{N}$ during the northern winter (November 1979-March 1980); in Fig. 10, comparisons are made with $\overline{v^{\prime} T^{\prime}}$ at $60^{\circ} \mathrm{S}$ during the southern winter (May-Sep 1980). The ozone and temperature time series were smoothed using a 5-day boxcar filter prior to calculating time derivatives. Here $20 \mathrm{hPa}$ is chosen as the primary pressure level for monitoring $\overline{v^{\prime} T^{\prime}}$ because, as will be seen below, long-term variations increase in amplitude with increasing altitude and this is the highest-altitude level where daily NCEP data are readily available on compact disk. However, long-term variations in $\overline{v^{\prime} T^{\prime}}$ will also be investigated at lower levels $(50 \mathrm{hPa}, 100 \mathrm{hPa})$. In addition, model results obtained using $20-\mathrm{hPa} \overline{v^{\prime} T^{\prime}}$ data will be tested by repeating the analysis using data from these lower levels. Comparing Figs. 9 and 10, it is seen that $\overline{v^{\prime} T^{\prime}}$ at $60^{\circ} \mathrm{S}$ during the $\mathrm{SH}$ winter exhibits negative fluctuations (poleward $v^{\prime}$ deviations are negative in the $\mathrm{SH}$ ) whose amplitudes are generally less than those in the $\mathrm{NH}$. The latter property is a consequence of the wellknown higher amplitudes of planetary waves forced in the $\mathrm{NH}$ as compared to those in the SH.

Assuming the validity of Eqs. (8) and (11) for shortterm events, approximate empirical relationships should
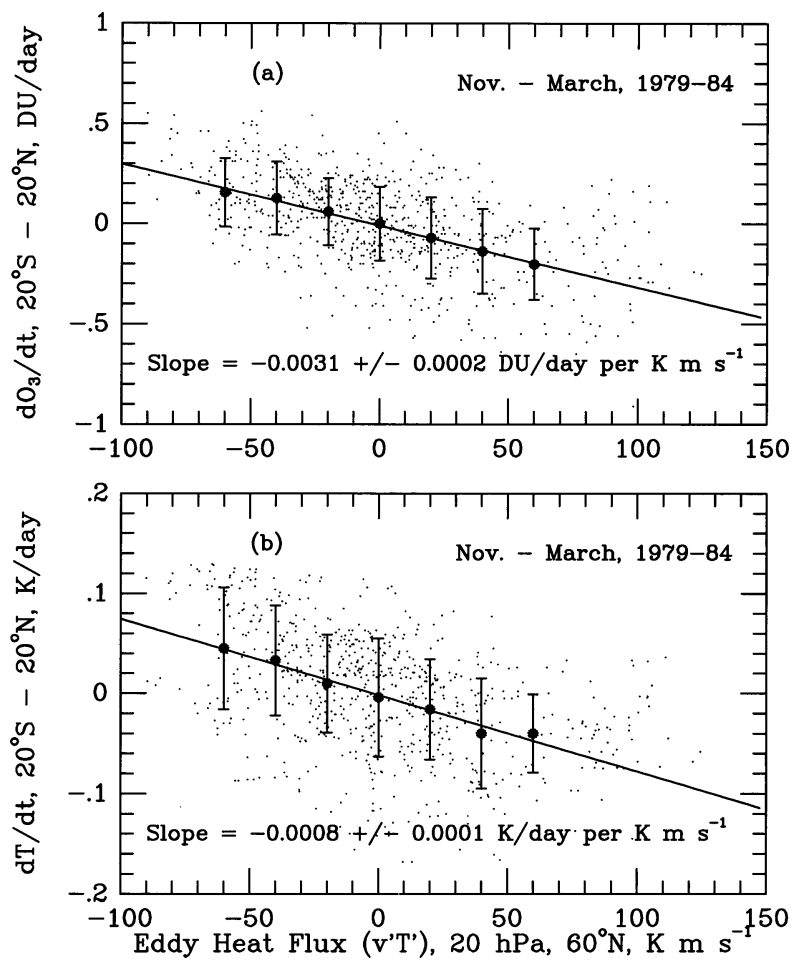

FIG. 11. Regression analysis results for (a) tropical column ozone tendencies and (b) tropical MSU channel 4 temperature tendencies vs $20-\mathrm{hPa}$ eddy heat flux at $60^{\circ} \mathrm{N}$. The small points represent individual daily data points for five winters (Nov-Mar 1979-80 to 1983-84). The large solid points and error bars represent means and standard errors for data points within a series of eddy heat flux bins centered on -60 , $-40,-20,0,20,40$, and $60 \mathrm{~K} \mathrm{~m} \mathrm{~s}^{-1}$. Regression lines are fit to the large solid points.

exist between daily tropical ozone tendencies, tropical temperature tendencies, and extratropical wave forcing, in both hemispheres. To estimate these relationships, we have used regression methods with results shown in Fig. 11 for the $\mathrm{NH}$ and in Fig. 12 for the SH. To represent the wave forcing, $\overline{v^{\prime} T^{\prime}}$ at $\left(20 \mathrm{hPa}, 60^{\circ} \mathrm{N}\right)$ during the northern winter and at $\left(20 \mathrm{hPa}, 60^{\circ} \mathrm{S}\right)$ during the southern winter are employed. In Fig. 11, the points are individual daily values for the November-March period and for five years from 1979-80 to 1983-84. In Fig. 12, the points are for the May-September 1979-83 period. To ensure that only short-term (less than 1 month) variations were considered, each 5-month interval was detrended by fitting a quadratic polynomial to the data and removing it prior to the regression analysis. In Fig. 11, the solid circles and error bars indicate means and standard deviations, respectively, for bins centered on $-60,-40,-20$, $0,20,40$, and $60 \mathrm{~K} \mathrm{~m} \mathrm{~s}^{-1}$. As seen in Fig. 12, the relative weakness of wave-forcing events in the $\mathrm{SH}$ increases the difficulty of estimating the regression coefficients. To be consistent with the analysis of the NH data shown in Fig. 11 , bins are chosen to be centered on $-20,0$, and $20 \mathrm{~K}$ $\mathrm{m} \mathrm{s}^{-1}$ in Fig. 12. The regression lines shown are fit to the means but differ only slightly from those obtained 

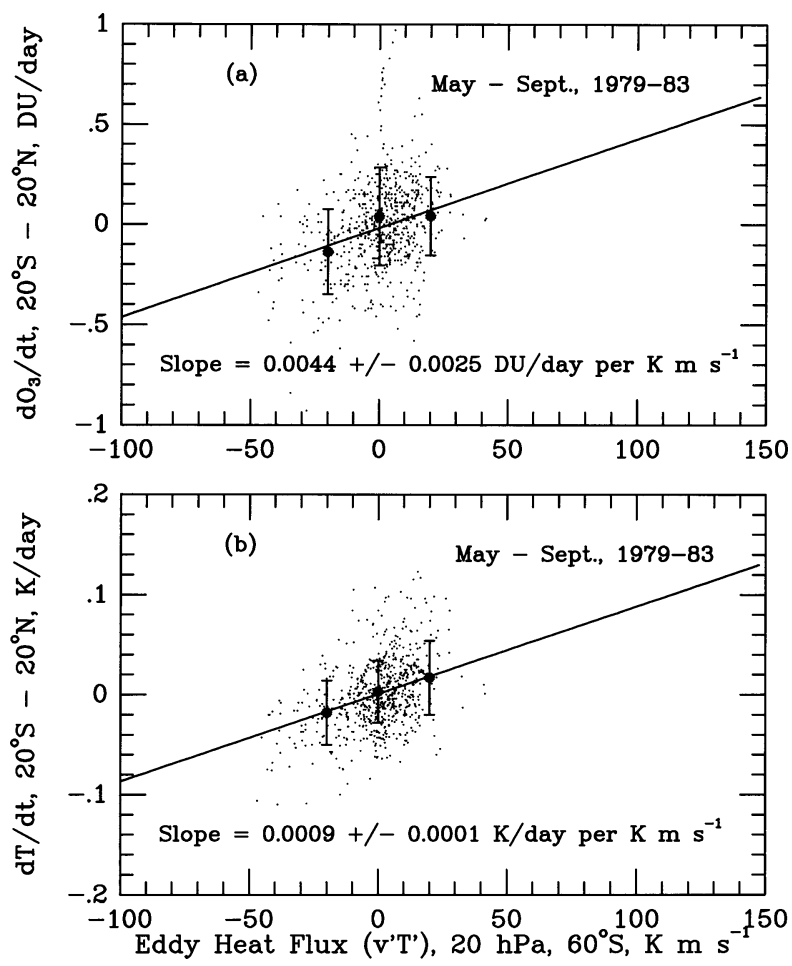

FIG. 12. Same format as in Fig. 11 but for five SH winters (MaySep 1979-83) using 20-hPa eddy heat fluxes at $60^{\circ} \mathrm{S}$. The large solid points and error bars represent means and standard errors for data points within eddy heat flux bins centered on $-20,-10,0,10$, and $20 \mathrm{~K} \mathrm{~m}$ $\mathrm{s}^{-1}$. The regression line is fit to the solid points.

when all points are considered. As indicated in the figures, for short (days to weeks) timescales, the results of this analysis imply empirical relationships of the form:

$$
\begin{aligned}
\frac{d O_{3}}{d t} & \simeq A_{\mathrm{N}} \overline{v^{\prime} T^{\prime}}{ }_{60^{\circ} \mathrm{N}}, \\
\frac{d T}{d t} & \simeq B_{\mathrm{N}} \overline{v^{\prime} T^{\prime}{ }_{60^{\circ} \mathrm{N}},} \\
\frac{d O_{3}}{d t} & \simeq A_{\mathrm{S}} \overline{v^{\prime} T^{\prime}}{ }_{60^{\circ} \mathrm{S}}, \\
\frac{d T}{d t} & \simeq B_{\mathrm{S}} \overline{v^{\prime} T^{\prime}}{ }_{60^{\circ} \mathrm{S}},
\end{aligned}
$$

where $\mathrm{O}_{3}$ represents total column ozone in the Tropics $\left(20^{\circ} \mathrm{S}-20^{\circ} \mathrm{N}\right), T$ represents tropical MSU4 temperature, and $A_{\mathrm{N}}, B_{\mathrm{N}}, A_{\mathrm{S}}$, and $B_{\mathrm{S}}$ are regression coefficients with amplitudes $A_{\mathrm{N}}=-0.0031 \pm 0.0002 \mathrm{DU}_{\mathrm{day}^{-1}}$ per K m $\mathrm{s}^{-1}, B_{\mathrm{N}}=-0.0008 \pm 0.0001 \mathrm{~K}_{\text {day }}{ }^{-1}$ per K m s${ }^{-1}, A_{\mathrm{S}}$ $=0.0044 \pm 0.0025 \mathrm{DU}^{-1 a y}{ }^{-1}$ per $\mathrm{K} \mathrm{m} \mathrm{s}^{-1}$, and $B_{\mathrm{S}}=$ $0.0009 \pm 0.0001 \mathrm{~K} \mathrm{day}^{-1}$ per $\mathrm{K} \mathrm{m} \mathrm{s}{ }^{-1}$. Although $A_{\mathrm{S}}$ tends to be larger than $A_{\mathrm{N}}$ when using eddy heat flux data at $20 \mathrm{hPa}$, the standard deviations are much larger for $A_{\mathrm{S}}$ and there is no a priori reason to expect a larger sensitivity to SH wave forcing than to $\mathrm{NH}$ wave forcing. Repetition of the same regression analysis using eddy heat flux data
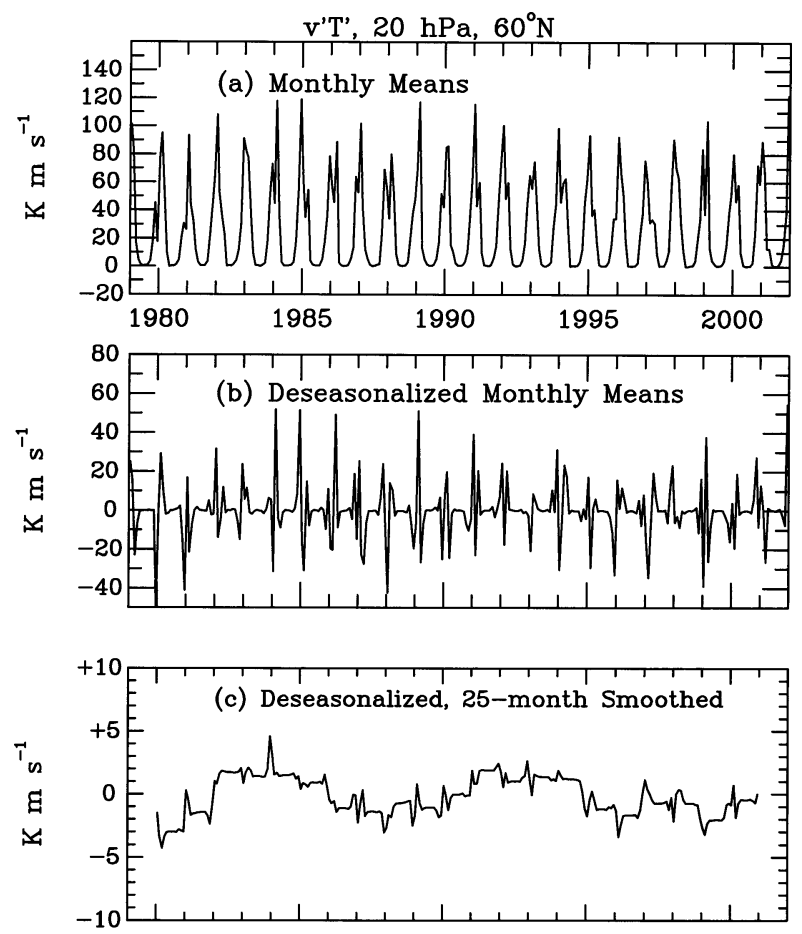

FIG. 13. Time series of monthly mean eddy heat flux at $(20 \mathrm{hPa}$, $60^{\circ} \mathrm{N}$ ), calculated from daily NCEP reanalysis data. (a) The monthly means; (b) deviations from long-term monthly means; and (c) the result of applying a 25 -month boxcar filter to the deseasonalized monthly means.

at $50 \mathrm{hPa}$ rather than $20 \mathrm{hPa}$ yields coefficients with nearly the same amplitudes in both hemispheres. Specifically, when using 50-hPa eddy heat flux data, we obtain coefficients with amplitudes of $A_{\mathrm{N}}=-0.0055 \pm$ $0.0004 \mathrm{DU}_{\text {day }^{-1}}$ per K m s${ }^{-1}, B_{\mathrm{N}}=-0.0013 \pm 0.0001$ $\mathrm{K}_{\text {day }}{ }^{-1}$ per $\mathrm{K} \mathrm{m} \mathrm{s}^{-1}, A_{\mathrm{S}}=0.0052 \pm 0.0031 \mathrm{DU}_{\text {day }}{ }^{-1}$ per $\mathrm{K} \mathrm{m} \mathrm{s}^{-1}$, and $B_{\mathrm{s}}=0.0010 \pm 0.0002 \mathrm{~K} \mathrm{day}^{-1}$ per $\mathrm{K} \mathrm{m} \mathrm{s}^{-1}$. We therefore conclude that there is no significant difference in regression coefficient amplitudes in the two hemispheres.

Given that empirical regression relationships between ozone and temperature in the tropical lower stratosphere and extratropical wave forcing occurring on short timescales are available, it is next of interest to investigate possible long-term variations in the wave forcing and how these may influence tropical variations. Figure 13 shows time series of monthly mean $\overline{v^{\prime} T^{\prime}}$ at $20 \mathrm{hPa}, 60^{\circ} \mathrm{N}$ for the period 1979-2001. As seen in Fig. 13a, significant interannual variations in the eddy heat flux are present. In some years, maximum (January) means are more than $110 \mathrm{~K} \mathrm{~m} \mathrm{~s}^{-1}$ while in other years, maximum monthly means are less than $80 \mathrm{~K} \mathrm{~m} \mathrm{~s}^{-1}$. These differences are emphasized further in Fig. 13b, which shows deviations from long-term monthly means. Although interannual variability dominates, a close examination indicates some evidence for decadal variability. To estimate the decadal variation, a 25-month boxcar filter was applied to the deseasonalized monthly means with a result shown in 

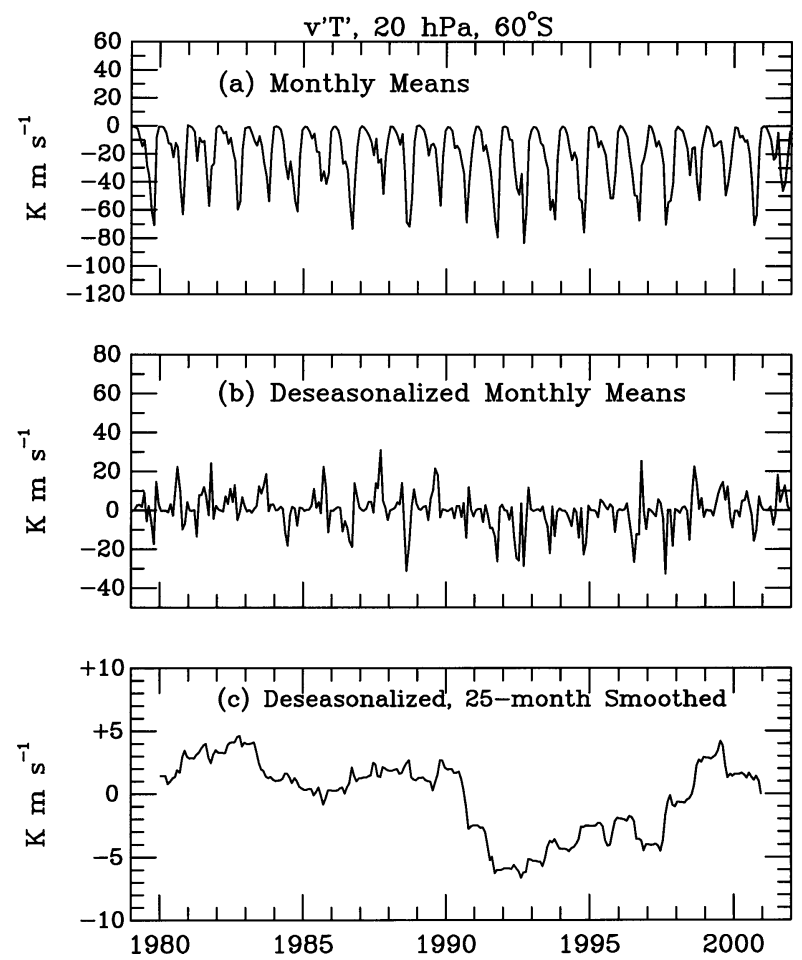

FIG. 14. Same format as in Fig. 13 but for monthly mean eddy heat flux at $\left(20 \mathrm{hPa}, 60^{\circ} \mathrm{S}\right)$.

Fig. 13c (25 months was chosen as the filter length to minimize interannual variability associated with the QBO). This procedure also assists in reducing the effects of possible random errors in the NCEP data. A decadal variation with a peak-to-peak amplitude of approximately $4 \mathrm{~K} \mathrm{~m} \mathrm{~s}^{-1}$ and a period of $9-10$ years is evident. A repetition of the $\mathrm{NH}$ calculations for the SH (Fig. 14) also yields evidence for a decadal variation in $20 \mathrm{hPa}$ $\overline{v^{\prime} T^{\prime}}$ at $60^{\circ} \mathrm{S}$, but with an opposite sign (again, because poleward $v^{\prime}$ deviations are negative in the $\mathrm{SH}$ ). As seen in Fig. 14c, the decadal variation in the SH is more irregular than that in the $\mathrm{NH}$. This may reflect, at least partly, reduced data quality in the SH where radiosonde stations near $60^{\circ} \mathrm{S}$ are less numerous and less evenly distributed in longitude.

In this study, we have adopted wave flux statistics based on NCEP reanalysis data (Kalnay et al. 1996). Here, the word "reanalysis" implies the application of a global data assimilation model to the entire data record for the purpose of minimizing artificial jumps associated with changes in the data assimilation system. Currently, the NCEP reanalysis data is the only reanalysis record that covers the entire 23-yr period of the study. However, one alternate reanalysis dataset covering the period 197993 has been compiled by the European Centre for Medium-Range Weather Forecasts (ECMWF). Also, operational data products not reanalyzed using a single assimilation model have been compiled at the NCEP Climate Prediction Center (CPC) as well as at the ECMWF.
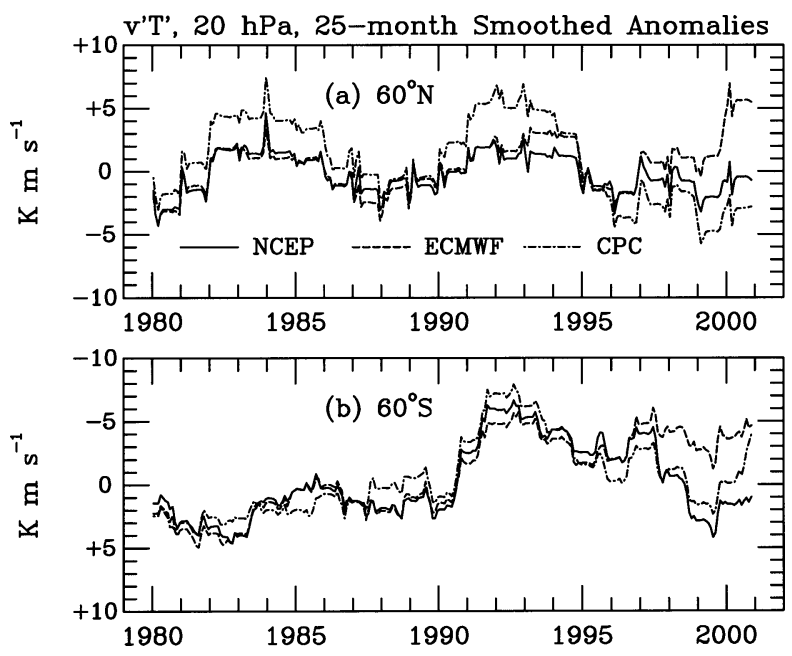

FIG. 15. Comparison of 25-month smoothed anomalies of $\overline{v^{\prime} T^{\prime}}$ calculated using different data sources at (a) $\left(20 \mathrm{hPa}, 60^{\circ} \mathrm{N}\right)$ and (b) $(20$ $\left.\mathrm{hPa}, 60^{\circ} \mathrm{S}\right)$. The solid lines represent values calculated using NCEP reanalysis data; the dashed lines are calculated using ECMWF reanalysis data for the period 1979-93 and using ECMWF operational analyses during 1994-2001; the dot-dashed lines are calculated using CPC operational analyses (see the text).

Figure 15 compares 25 -month smoothed $\overline{v^{\prime} T^{\prime}}$ anomalies at $\left(20 \mathrm{hPa}, 60^{\circ} \mathrm{N}\right)$ and at $\left(20 \mathrm{hPa}, 60^{\circ} \mathrm{S}\right)$ calculated using (a) the NCEP reanalysis data; (b) the ECMWF reanalysis data for 1979-93 and ECMWF operational data for 1994-2001; and (c) the CPC operational data. As can be seen, values calculated using the NCEP and ECMWF reanalysis data are in excellent agreement in both hemispheres during the period of overlap (1979-93). However, the CPC operational data differ significantly from the two reanalysis records during this period. Also, both the CPC and ECMWF operational data records differ markedly from the NCEP reanalysis data during the 1994-2001 period. Since reanalysis records are generally preferred over operational products for long-term stability, the NCEP and ECMWF data are considered to be more reliable than the CPC data during the 1979-93 period. During the 1994-2001 period, we also consider the NCEP reanalysis data to be more reliable than the CPC and ECMWF operational products. From comparisons such as these, we conclude that the NCEP reanalysis data record is the single most reliable record available for the entire 1979-2001 period. However, we also emphasize that the accuracy of this record is still limited by radiosonde data quality, especially at higher latitudes in the SH.

Calculations of 25-month smoothed eddy heat fluxes at other pressure levels in the lower stratosphere (Fig. 16) show that the amplitude of the decadal variation of $\overline{v^{\prime} T^{\prime}}$ (like that of $\overline{v^{\prime} T^{\prime}}$ itself) decreases with decreasing altitude. But the form of the temporal variation is very similar at all levels in both hemispheres. For this reason, as will be seen below, although $20-\mathrm{hPa} \overline{v^{\prime} T^{\prime}}$ data are adopted here as a primary measure of extratropical 


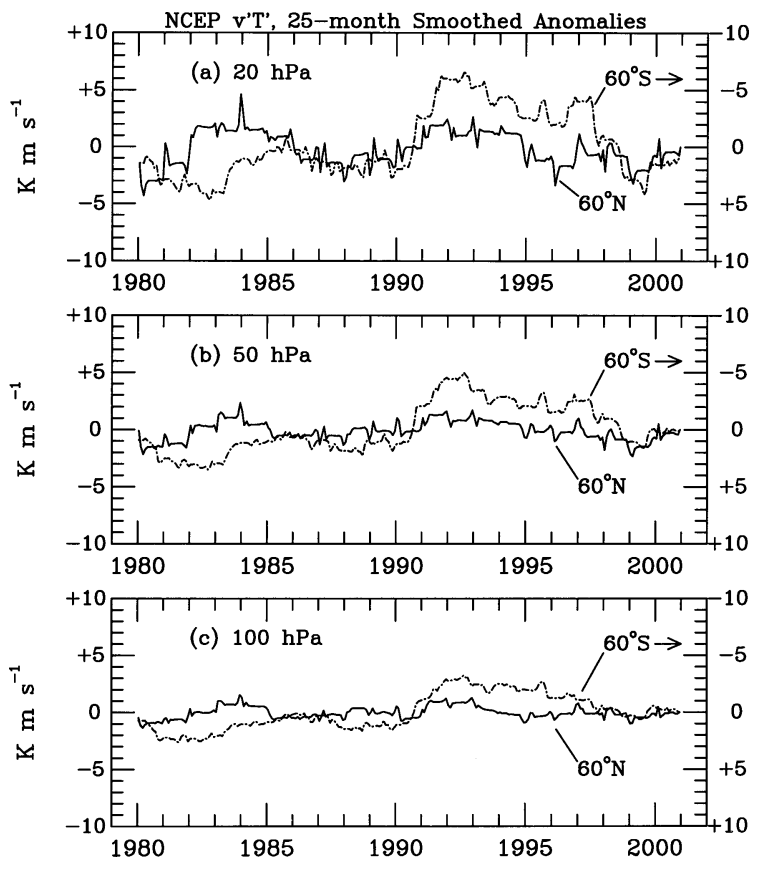

FIG. 16. Comparison of 25-month smoothed anomalies of $\overline{v^{\prime} T^{\prime}}$ at $60^{\circ} \mathrm{N}$ and $60^{\circ} \mathrm{S}$ and at three different pressure levels in the lower stratosphere. Note that the vertical scale for the $60^{\circ} \mathrm{S}$ data has been inverted.

wave forcing, repetitions of the analysis using $\overline{v^{\prime} T^{\prime}}$ data at lower levels yield comparable results.

Finally, we wish to estimate the contributions of the decadal variations of extratropical wave forcing in the $\mathrm{NH}$ and SH shown in Figs. 14, 15, and 16 to the observed quasi-decadal oscillation of tropical column ozone and lower-stratospheric temperature shown in Fig. 1. For this purpose, it is useful to consider a simplified model based on Eqs. (7), (10), and (12):

$$
\begin{gathered}
\frac{d O_{3}}{d t} \simeq A_{\mathrm{N}}{\overline{v^{\prime} T^{\prime}}}_{60^{\circ} \mathrm{N}}+A_{\mathrm{S}}{\overline{v^{\prime} T^{\prime}}}_{60^{\circ} \mathrm{S}}-\frac{\mathrm{O}_{3}}{\tau_{c}}, \\
\frac{d T}{d t} \simeq B_{\mathrm{N}}{\overline{v^{\prime} T^{\prime}}}_{60^{\circ} \mathrm{N}}+B_{\mathrm{S}}{\overline{v^{\prime} T^{\prime}}}_{{ }_{60}^{\circ} \mathrm{S}}-\frac{T}{\tau_{r}},
\end{gathered}
$$

where ${\overline{v^{\prime} T^{\prime}}}_{60^{\circ} \mathrm{N}}$ and ${\overline{v^{\prime} T^{\prime}}}_{60^{\circ} \mathrm{s}}$ represent deviations from long-term means for each month and where $\mathrm{O}_{3}$ and $T$ at $t=0$ represent deviations from their equilibrium values. The model assumes that long-term $(>1 \mathrm{yr})$ anomalies in the upwelling rate are mainly caused by changes in extratropical wave forcing. Note that this assumption may not be valid on some timescales (e.g., seasonal) when other processes contribute measurably to the upwelling rate. The model further assumes that $\mathrm{NH}$ and $\mathrm{SH}$ wave forcing of the tropical upwelling rate (and hence dynamically forced ozone and temperature tendencies) can be represented as a simple linear superposition of the two forcing components. For short-term (days to a few weeks) variations, the chemical decay and radiative cooling terms on the right sides of (13) and (14) can be neglected so that (13) and (14) reduce to Eqs. (12a,b) during the

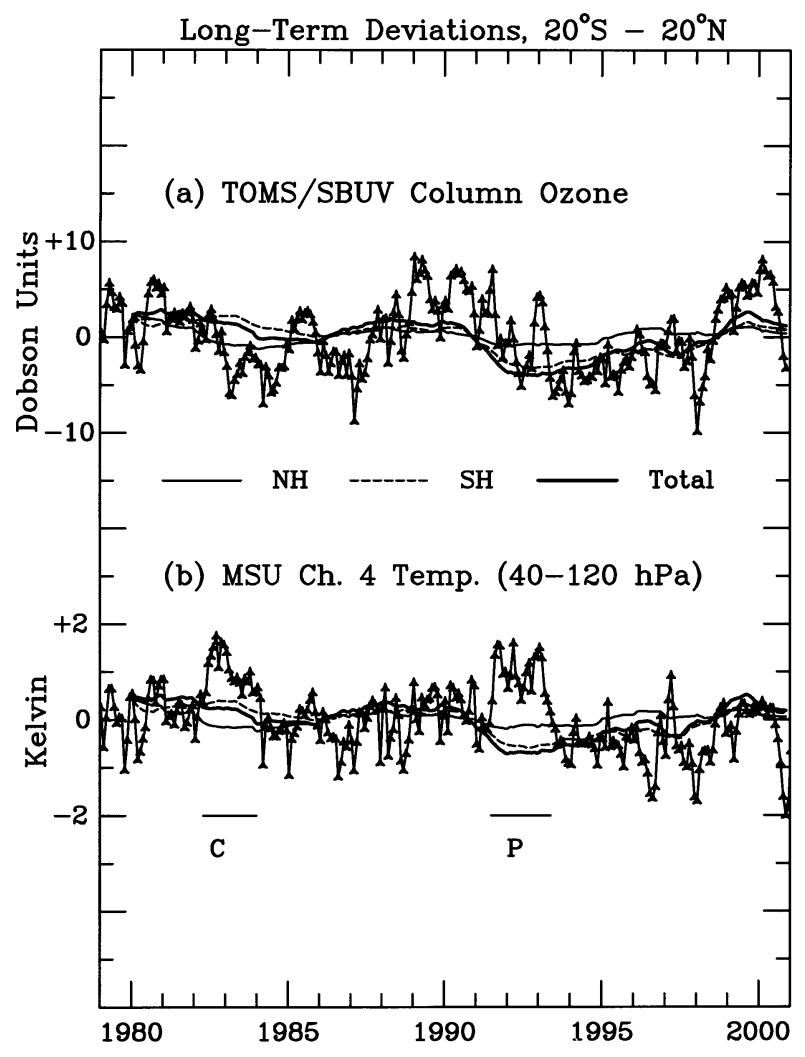

FIG. 17. Comparison of model data with the observed column ozone and MSU4 temperature anomalies for tropical latitudes. The thin solid line represents the contribution to the model data from wave forcing in the NH. The dashed line represents the contribution from wave forcing in the $\mathrm{SH}$.

northern winter and to Eq. (12c,d) during the southern winter. For long-term $(>1 \mathrm{yr})$ variations, the chemical decay and radiative cooling terms on the right sides of (13) and (14) are not negligible. In order to integrate (13) and (14), we choose $t=0$ in January 1980 when the smoothed eddy heat flux data begin. Because any initial value for $\mathrm{O}_{3}$ and $T$ decays away with time constants of $\tau_{c}$ and $\tau_{r}$, results of the integration do not depend strongly on the choice of initial values. At $t=0$, we choose $O_{3}$ $\simeq 2.5 \mathrm{DU}$ and $T \simeq 0.5 \mathrm{~K}$, consistent with the observed deviations near 1980. Finally, in view of the reduced accuracy of the regression coefficients $A_{\mathrm{S}}$ and $B_{\mathrm{S}}$ as discussed in relation to Figs. 11 and 12, we assume here that $A_{\mathrm{S}}$ and $B_{\mathrm{S}}$ have the same absolute amplitudes (but opposite signs) as $A_{\mathrm{N}}$ and $B_{\mathrm{N}}$, respectively. Adopting $\tau_{c}$ $\simeq 6$ months and $\tau_{r} \simeq 100$ days, (13) and (14) were then integrated in time to yield the model tropical total ozone and lower-stratospheric temperature variations shown as the heavy smooth curves in Fig. 17. The separate contributions of wave forcing in the $\mathrm{NH}$ and $\mathrm{SH}$ are shown by the thin solid and dashed lines, respectively. During most time intervals, the $20-\mathrm{hPa} \mathrm{SH}$ wave forcing component makes roughly the same contribution to the decadal ozone and temperature variations as the $\mathrm{NH}$ forcing component. During the 1991-97 period, the SH forcing 


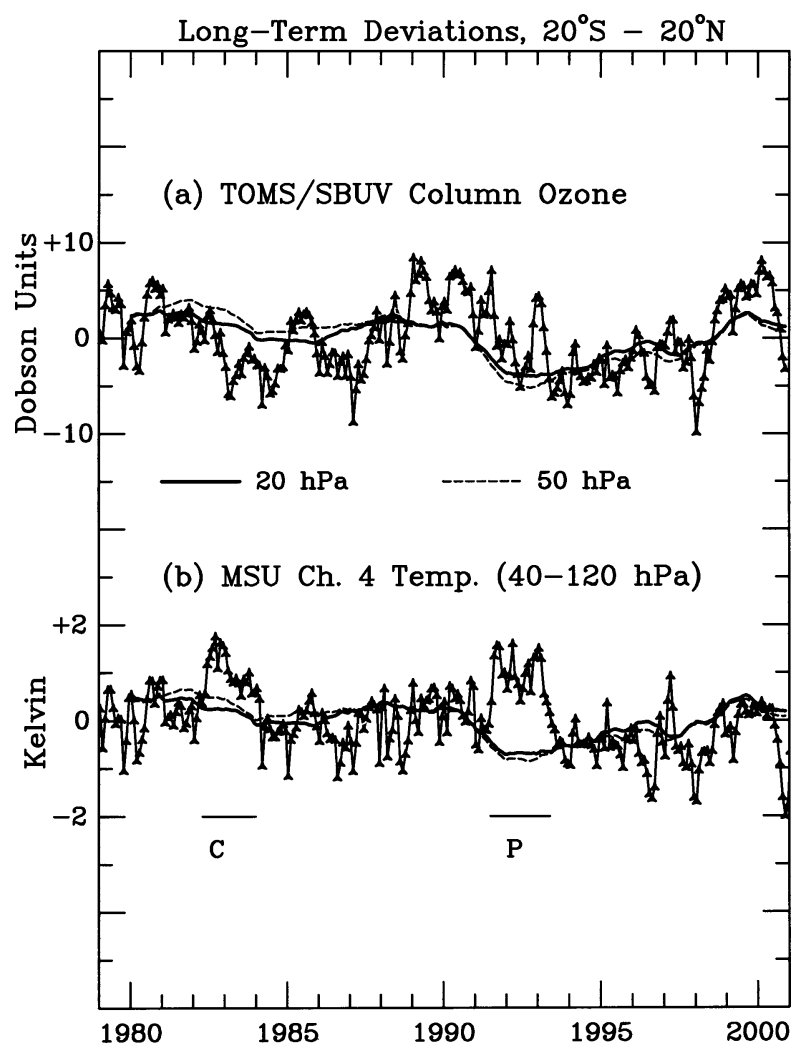

FIG. 18. The thin dashed lines represent model data calculated using $50-\mathrm{hPa}$ heat flux data. The thick solid lines represent model data calculated using $20-\mathrm{hPa}$ heat flux data. Remainder of figure is in the same format as in Fig. 17.

appears to dominate. However, this reflects mainly the irregular increase in wave forcing occurring during the early 1990s in the SH (see Fig. 16a), which may be at least partly due to data inaccuracies, as discussed in relation to Fig. 14c. Overall, we consider that the model results shown in Fig. 17 provide substantial evidence that wave forcings in both hemispheres may be significant contributors to tropical decadal variability.

For comparison, the tropical total ozone and MSU4 temperature anomalies of Fig. 1 are also replotted in Fig. 17. The agreement between the model variations and the observed variations is imperfect in several respects. In the case of the temperature variation, the temperature increases associated with volcanic aerosol heating following the El Chichon and Pinatubo eruptions are not accounted for. In the case of the ozone variation, the model curve is higher than the observed deviations during the first part of the record. Part of this disagreement may reflect inaccuracies in the NCEP eddy heat flux data resulting from the sparsity of radiosonde measurements near $60^{\circ} \mathrm{S}$. Nevertheless, the model decadal variations are comparable in amplitude to the observed variations and have approximately the correct phase.

To test the sensitivity of the results shown in Fig. 17 to changes in input parameters, several alternate ap-

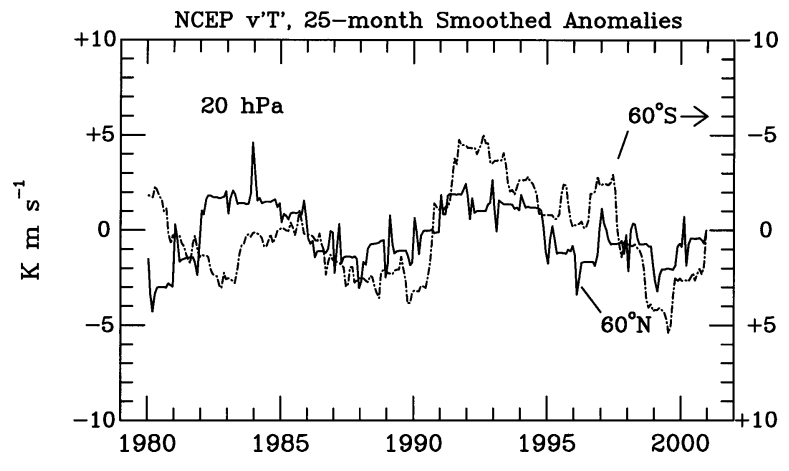

FIG. 19. Comparison of $\overline{v^{\prime} T^{\prime}}$ smoothed anomalies at $\left(20 \mathrm{hPa}, 60^{\circ} \mathrm{S}\right)$ and $\left(20 \mathrm{hPa}, 60^{\circ} \mathrm{N}\right)$ after removing the quadratic trend from the $60^{\circ} \mathrm{S}$ time series. The scale for the $60^{\circ} \mathrm{S}$ data has been inverted.

proaches were applied. First, to investigate whether the results were dependent heavily on use of the 20-hPa wave flux data, the analysis was repeated using NCEP 50-hPa wave fluxes (Fig. 16b). This required recalculation of regression relationships between daily ozone and temperature tendencies and 50-hPa eddy heat fluxes at both $60^{\circ} \mathrm{N}$ and $60^{\circ} \mathrm{S}$ in the same manner as illustrated in Figs. 11 and 12 . As already noted above, when using 50-hPa heat flux data, we obtain $A_{\mathrm{N}}=-0.0055 \pm 0.0004 \mathrm{DU}$ day $^{-1}$ per $\mathrm{K} \mathrm{m} \mathrm{s}^{-1}$ and $B_{\mathrm{N}}=-0.0013 \pm 0.0001 \mathrm{~K} \mathrm{day}^{-1}$ per $\mathrm{K} \mathrm{m} \mathrm{s}^{-1}$. To be consistent with the $20-\mathrm{hPa}$ analysis, for the model calculations we have assumed that the absolute amplitudes of $A_{\mathrm{S}}$ and $B_{\mathrm{S}}$ are approximately equal to the more accurately estimated amplitudes of $A_{\mathrm{N}}$ and $B_{\mathrm{N}}$. Although these regression coefficient amplitudes are larger than obtained when using $20-\mathrm{hPa}$ eddy heat flux data, these increases are offset by the reduced amplitude of the decadal oscillation of $\overline{v^{\prime} T^{\prime}}$ shown in Fig. 16b. Consequently, the resulting model tropical ozone and lower-stratospheric temperature variations using the 50$\mathrm{hPa} \overline{v^{\prime} T^{\prime}}$ data differ only slightly from those calculated using the 20-hPa $\overline{v^{\prime} T^{\prime}}$ data (Fig. 18). Although not shown in Fig. 18, a calculation of the separate contributions of $\mathrm{SH}$ and $\mathrm{NH}$ forcing components using the 50-hPa $\overline{v^{\prime} T^{\prime}}$ data indicates that the $\mathrm{SH}$ forcing again dominates over the $\mathrm{NH}$ forcing during the 1991-97 period but is comparable to the $\mathrm{NH}$ forcing during other periods.

Last, it can be seen in Fig. 16 that the SH wave forcing time record is characterized by a significant positive trend. The latter may reflect either data problems or a real trend associated with the Antarctic ozone hole and an increasingly persistent Antarctic polar vortex. To test whether removing the trend would improve the model agreement with the observed long-term variations of tropical ozone and lower-stratospheric temperature, a quadratic polynomial was least squares fitted to the $\mathrm{SH}$ (25month smoothed) wave flux data and removed. Figure 19 compares the "detrended" $20-\mathrm{hPa} \overline{v^{\prime} T^{\prime}}$ time series at $60^{\circ} \mathrm{S}$ (dot-dashed line) with that at $60^{\circ} \mathrm{N}$ (solid line). It is seen that the detrending does improve the correlation between the (inverted) $60^{\circ} \mathrm{S}$ time series and the $60^{\circ} \mathrm{N}$ time series. As shown in Fig. 20, substitution of the de- 


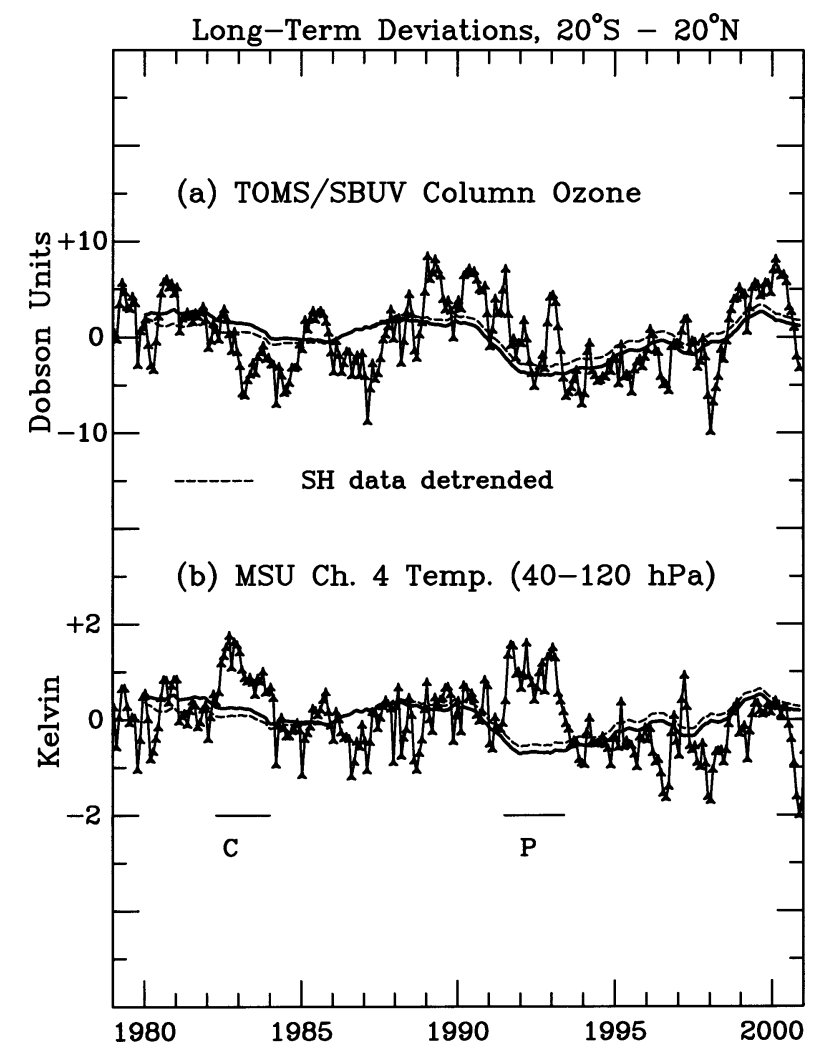

FIG. 20. The thick solid lines represent the predictions of the model discussed in the text using $20-\mathrm{hPa} \overline{v^{\prime} T^{\prime}}$ data at $60^{\circ} \mathrm{S}$ and $60^{\circ} \mathrm{N}$ (same as in Figs. 17 and 18). The dashed lines represent the predictions of the same model after detrending the $\overline{v^{\prime} T^{\prime}}$ data at $60^{\circ} \mathrm{S}$ (see the text).

trended $60^{\circ} \mathrm{S} \overline{v^{\prime} T^{\prime}}$ time series for the original $60^{\circ} \mathrm{S}$ $\overline{v^{\prime} T^{\prime}}$ series in the model causes a slightly better agreement of the model data with the observed ozone and temperature data records.

\section{Conclusions and discussion}

The analysis of section 3 indicates that decadal variability of the equatorial quasi-biennial wind oscillation can explain only a small fraction, at most, of the observed QDO of tropical lower-stratospheric ozone and temperature. After simulating the QBO component of equatorial ozone and temperature variability using the model of Hasebe (1994), a residual (observed minus model data) decadal variation remains with an amplitude comparable to that of the tropical mean ozone and temperature variation shown in Fig. 1. The residuals were found to correlate approximately with indicators of solar UV irradiance variability on the 11-yr timescale. As emphasized, however, in section 3, the Hasebe (1994) model employs idealized parameterizations that cannot fully reproduce all observed characteristics of the ozone and temperature QBO in the Tropics. A final assessment of QBO influences on tropical decadal variability must therefore await the application of more detailed models for this purpose.
The analysis of section 4 led to the conclusion that decadal variations of extratropical wave forcing in both hemispheres, as estimated using NCEP reanalysis data, are potentially much more capable (as compared to decadal variability of the QBO) of producing long-term variations in tropical lower-stratospheric temperature and ozone that have amplitudes and phases similar to those that are observed. Results based on both $20-$ and $50-\mathrm{hPa}$ wave flux data indicated that both $\mathrm{NH}$ and $\mathrm{SH}$ wave forcings make nonnegligible contributions to decadal variability of the tropical lower stratosphere. Remaining differences between the observed and model variations shown in Fig. 18 may be attributed to (a) unmodeled effects of volcanic forcing; (b) simplicity of the model; and (c) inaccuracies in the NCEP reanalysis data, especially near $60^{\circ} \mathrm{S}$ where the $\mathrm{SH}$ wave forcing was monitored. It may even still be questioned whether the NCEP reanalysis data provide the best overall assessment of decadal changes in extratropical wave forcing. In particular, the decadal variations in ECMWF analyses look significantly different in the SH, especially after 1996 (see Fig. 15b). However, as discussed in relation to Fig. 15, the ECMWF data consist of operational data after 1994 rather than reanalysis data and may therefore be considered to be less reliable than the NCEP reanalysis data during this time period. It is for this reason that we have used only the NCEP data in the model calculations.

The analysis of this paper does not directly prove any relationship between the 11-yr solar cycle and extratropical wave forcing. However, the approximate correlation of the decadal variation of tropical ozone and temperature with the 11-yr solar cycle (Figs. 5 and 7), suggests a possible downward influence on the circulation and, therefore, on the wave driving in the extratropics (cf. Haynes et al. 1991).

Direct photochemical effects of decadal solar UV variations on stratospheric ozone occur primarily in the middle and upper stratosphere (Brasseur 1993; Haigh 1996; Shindell et al. 1999). As indicated in the introduction, it was therefore unexpected that a number of analyses of both total ozone and meteorological data extending over a period of more than four decades have suggested a significant response of the lower stratosphere to decadal solar variability (Labitzke and van Loon 1988, 1993; Labitzke 2001; Zerefos et al. 1997; Hood 1997). As a rule, general circulation models have been only marginally successful in simulating the lower-stratospheric QDO for realistic changes in solar spectral irradiance (Kodera et al. 1991; Rind and Balachandran 1995; Haigh 1999; Shindell et al. 1999). In order to explain the apparent occurrence of significant lower-stratospheric effects of solar forcing on the 11-yr timescale, it has been proposed that solar UV variations, like other weak forcings (QBO, volcanic aerosols), may be capable of influencing the selection of preferred dynamical regimes in the winter stratosphere (Holton 1994; Kodera 1995). For example, depending on the phase of the QBO, solar UV-induced changes in upper-stratospheric zonal winds may modify 
interactions of planetary waves with the mean flow sufficiently to perturb the winter stratospheric circulation into one or the other of its preferred modes (e.g., Rind and Balachandran 1995). This would assist in understanding how energetically weak solar UV forcing could produce detectable changes in lower-stratospheric circulation. This proposed mechanism is only operative during the winter and assumes that solar UV-induced zonal wind perturbations in early winter will propagate downward and interact nonlinearly with planetary waves to modify the preexisting wind field (Hines 1974; see also Haynes et al. 1991; Baldwin and Dunkerton 1999). It has been further suggested that secondary effects of these upper-level wind changes on the mean meridional (Brewer-Dobson) circulation are possible (Kodera and Kuroda 2002).

In support of the hypothesis that the direct upper-stratospheric effects of solar UV variations may have nonnegligible lower-stratospheric consequences, recent observational and theoretical studies indicate that the QBO in the upper stratosphere exerts a significant influence on winter lower stratospheric circulation (Gray et al. 2001a,b). The amplitudes of quasi-decadal zonal wind changes in the upper stratosphere (Kodera 1995; Hood et al. 1993), which are hypothesized to influence wave driving and produce lower-stratospheric effects, are much larger than calculated by most existing models that assume realistic solar UV variations. Although most of these studies have focused on the NH winter circulation, upper-stratospheric zonal wind data show apparent solar cycle variations near the time of winter solstice in both hemispheres that are larger than expected theoretically (see Fig. 5c of Hood et al. 1993). In addition, statistical studies have found evidence for apparent solar cycle signals in NCEP geopotential height and temperature data in the lower stratosphere in both hemispheres (Labitzke 2001, and references therein) and in TOMS column ozone and MSU4 temperature data in both hemispheres (Hood 1997). The fact that we find significant SH, as well as NH, forcing of decadal variability in the Tropics is therefore not inconsistent with earlier studies.

Acknowledgments. The TOMS/SBUV ozone processing team (led by R. Stolarski and R. McPeters) at the Goddard Space Flight Center and the MSU processing team (led by J. Christy) at the University of Alabama at Huntsville provided the column ozone and MSU channel 4 temperature data used in this work. The NCEP-NCAR reanalysis data team at the NCEP Climate Prediction Center provided the data used to calculate meridional eddy heat fluxes. B. Naujokat of the Free University of Berlin kindly supplied equatorial zonal wind records needed for the QBO model calculation. The NOAA Space Environment Laboratory provided Nimbus-7 SBUV Mg II data and the NASA UARS/SUSIM team provided the SUSIM Mg II data. We especially thank K. Kodera for useful criticisms of an earlier manuscript. W. Randel and K. Kodera also generously provided copies of relevant papers in advance of publication. W. Randel and $\mathrm{F}$. $\mathrm{Wu}$ provided the ECMWF and CPC wave flux statistics used to produce Fig. 15. Constructive criticisms by W. Randel and two anonymous reviewers significantly improved the final paper. This work was supported by grants from the NASA Atmospheric Chemistry Modeling and Analysis Program and the Living With a Star Program.

\section{REFERENCES}

Andrews, D. G., J. R. Holton, and C. B. Leovy, 1987: Middle Atmosphere Dynamics. Academic Press, 489 pp.

Baldwin, M. P., and T. J. Dunkerton, 1999: Propagation of the Arctic oscillation from the stratosphere to the troposphere. J. Geophys. Res., 104, 30 937-30 945.

_ and Coauthors, 2001: The quasi-biennial oscillation. Rev. Geophys., 39, 179-229.

Brasseur, G., 1993: The response of the middle atmosphere to longterm and short-term solar variability: A two-dimensional model. J. Geophys. Res., 98, 23 079-23 090.

— Reidel, $441 \mathrm{pp}$.

Brewer, A. W., 1949: Evidence for a world circulation provided by the measurements of helium and water vapour distribution in the stratosphere. Quart. J. Roy. Meteor. Soc., 75, 351-363.

Camp, C. D., M. S. Roulston, and Y. L. Yung, 2003: Temporal and spatial patterns of the interannual variability of total ozone in the Tropics. J. Geophys. Res., in press.

Chandra, S., 1986: The solar and dynamically induced oscillations in the stratosphere. J. Geophys. Res., 91, 2719-2734.

_ 1991: The solar UV related changes in total ozone from a solar rotation to a solar cycle. Geophys. Res. Lett., 18, 837-840.

Charney, J. G., and P. G. Drazin, 1961: Propagation of planetary-scale disturbances from the lower into the upper atmosphere. J. Geophys. Res., 66, 83-109.

Chipperfield, M. P., L. J. Gray, J. S. Kinnersley, and J. Zawodny, 1994: A two-dimensional model study of the QBO signal in SAGE II $\mathrm{NO}_{2}$ and $\mathrm{O}_{3}$. Geophys. Res. Lett., 21, 589-592.

Dunkerton, T. J., 1991: Nonlinear propagation of zonal winds in an atmosphere with Newtonian cooling and equatorial wavedriving. J. Atmos. Sci., 48, 236-263.

Fritz, S., and D. Soules, 1972: Planetary variations of stratospheric temperature. Mon. Wea. Rev., 100, 582-589.

Fusco, A. C., and M. L. Salby, 1999: Interannual variations of total ozone and their relationship to variations of planetary wave activity. J. Climate, 12, 1619-1629.

Garcia, R. R., 1987: On the mean meridional circulation of the middle atmosphere. J. Atmos. Sci., 44, 3599-3609.

Gray, L. J., E. F. Drysdale, T. J. Dunkerton, and B. N. Lawrence, 2001a: Model studies of the inter annual variability of the Northern Hemisphere winter circulation: The role of the quasi-biennial oscillation. Quart. J. Roy. Meteor. Soc., 127, 1413-1432.

_ S. J. Phipps, T. J. Dunkerton, M. P. Baldwin, E. F. Drysdale, and M. R. Allen, 2001b: A data study of the influence of the equatorial upper stratosphere on Northern Hemisphere stratospheric sudden warmings. Quart. J. Roy. Meteor. Soc., 127, 1985-2003.

Haigh, J. D., 1996: On the impact of solar variability on climate. Science, 272, 981-984.

- 1999: A GCM study of climate change in response to the 11year solar cycle. Quart. J. Roy. Meteor. Soc., 125, 871-892.

Hasebe, F., 1994: Quasi-biennial oscillations of ozone and diabatic circulation in the equatorial stratosphere. J. Atmos. Sci., 51, 729745.

Haynes, P. H., C. J. Marks, M. McIntyre, T. Shepherd, and K. Shine, 1991: On the "downward control" of extratropical diabatic circulations by eddy-induced mean zonal forces. J. Atmos. Sci., 48, 651-678. 
Heath, D., and B. Schlesinger, 1986: The mg 280-nm doublet as a monitor of changes in solar ultraviolet irradiance. J. Geophys. Res., 91, 8672-8682.

Hines, C. O., 1974: A possible mechanism for the production of sunweather correlations. J. Atmos. Sci., 31, 589-591.

Holton, J. R., 1990: On the global exchange of mass between the stratosphere and troposphere. J. Atmos. Sci., 47, 392-395.

_ 1994: The quasi-biennial oscillation in the earth's atmosphere and its links to longer period variability. The Solar Engine and Its Influence on Terrestrial Atmosphere and Climate, E. NesmeRibes, Ed., NATO ASI Series, Vol. 125, Springer-Verlag, 259273.

— , P. H. Haynes, M. E. McIntyre, A. R. Douglass, R. B. Rood, and L. Pfister, 1995: Stratosphere-troposphere exchange. Rev. Geophys., 33, 403-439.

Hood, L. L., 1997: The solar cycle variation of total ozone: Dynamical forcing in the lower stratosphere. J. Geophys. Res., 102, 13551370

_ 2003: Effects of solar UV variability on the stratosphere. Solar Variability and its Effect on the Earth's Atmospheric and Climate System, J. Pap et al., Eds., AGU Monograph Series, American Geophysical Union, in press.

_ ability of the stratosphere: Influence of long-term solar ultraviolet variations. J. Atmos. Sci., 50, 3941-3958.

Houghton, J. T., Y. Ding, D. J. Griggs, M. Noguer, P. J. van der Linden, X. Dai, K. Maskell, and C. A. Johnson, Eds., 2001: Climate Change 2001: The Scientific Basis. Cambridge University Press, $881 \mathrm{pp}$.

Kalnay, E., and Coauthors, 1996: The NCEP/NCAR 40-Year Reanalysis Project. Bull. Amer. Meteor. Soc., 77, 437-471.

Kodera, K., 1995: On the origin and nature of the interannual variability of the winter stratospheric circulation in the Northern Hemisphere. J. Geophys. Res., 100, 14 077-14 087.

— , and Y. Kuroda, 2002: Dynamical response to the solar cycle: Winter stratopause and lower stratosphere. J. Geophys. Res., 101, 4749, doi:10.1029/2002JD002224.

— M. Chiba, and K. Shibata, 1991: A general circulation model study of the solar and QBO modulation of the stratospheric circulation during the Northern Hemisphere winter. Geophys. Res. Lett., 18, 1209-1212.

Krishna Murthy, B. V., K. Parameswaran, and K. O. Rose, 1986: Temporal variations of the tropical tropopause characteristics. J. Atmos. Sci., 43, 914-922.

Labitzke, K., 2001: The global signal of the 11-year sunspot cycle in the stratosphere: Differences between solar maxima and minima. Meteor. Z., 10, 901-908.

— cycle, the QBO and the atmosphere, I, The troposphere and stratosphere in the Northern Hemisphere in winter. J. Atmos. Terr. Phys., 50, 197-206.

— , and M. P. McCormick, 1992: Stratospheric temperature increases due to Pinatubo aerosols. Geophys. Res. Lett., 19, 207-210.

_ nections between solar and atmospheric variability. Ann. Geophys., 11, 1084-1094.

Ling, X.-D., and J. London, 1986: The quasi-biennial oscillation of ozone in the tropical middle stratosphere: A one-dimensional model. J. Atmos. Sci., 43, 3122-3137.

McCormack, J. P., and D. E. Siskind, 2003: Simulations of the quasibiennial oscillation and its effect on stratospheric $\mathrm{H}_{2} \mathrm{O}, \mathrm{CH}_{4}$, and age of air with an interactive two-dimensional model. J. Geophys. Res., in press.

_ L. L. Hood, R. Nagatani, A. J. Miller, W. Planet, and R. McPeters, 1997: Approximate separation of volcanic and 11-year signals in the SBUV-SBUV/2 total ozone record over the 1979-1995 period. Geophys. Res. Lett., 24, 2729-2732.

McPeters, R., and Coauthors, 1996: Nimbus 7 Total Ozone Mapping Spectrometer (TOMS) data products user's guide. NASA Tech. Rep. 1384, 67 pp.

Newman, P. A., E. R. Nash, and J. E. Rosenfield, 2001: What controls the temperature of the Arctic stratosphere during the spring? $J$. Geophys. Res., 106, 19 999-20010.

Norton, W. A., 2001: Longwave heating of the tropical lower stratosphere. Geophys. Res. Lett., 28, 3653-3656.

Plumb, R. A., and R. C. Bell, 1982: A model of the quasi-biennial oscillation on an equatorial beta-plane. Quart. J. Roy. Meteor. Soc., 108, 335-352.

— namics of the tropical upwelling. J. Atmos. Sci., 56, 868-890.

Randel, W. J., 1993: Global variations of zonal mean ozone during stratospheric warming events. J. Atmos. Sci., 50, 3308-3321.

- and F. Wu, 1996: Isolation of the ozone QBO in SAGE II data by singular value decomposition. J. Atmos. Sci., 53, 2546-2559. - _ , and D. J. Gaffen, 2000: Interannual variability of the tropical tropopause derived from radiosonde data and NCEP reanalyses. J. Geophys. Res., 105, 15 509-15 523.

_, R. Garcia, and F. Wu, 2002a: Time-dependent upwelling in the tropical lower stratosphere estimated from the zonal-mean momentum budget. J. Atmos. Sci., 59, 2141-2152.

_ , F. Wu, and R. Stolarski, 2002b: Changes in column ozone correlated with the stratospheric EP flux. J. Meteor. Soc. Japan, 80, 849-862.

Rind, D., and N. K. Balachandran, 1995: Modeling the effects of UV variability and the QBO on the troposphere/stratosphere system. Part II: The troposphere. J. Climate, 8, 2080-2095.

Robock, A., 2000: Volcanic eruptions and climate. Rev. Geophys., 38, 191-220.

Salby, M., and P. Callaghan, 2000: Connection between the solar cycle and the QBO: The missing link. J. Climate, 13, 2652-2662.

Shindell, D., D. Rind, N. Balachandran, J. Lean, and P. Lonergan, 1999: Solar cycle variability, ozone, and climate. Science, 284, 305-308.

Soukharev, B. E., and L. L. Hood, 2001: Possible solar modulation of the equatorial quasi-biennial oscillation: Additional statistical evidence. J. Geophys. Res., 106, 14 855-14 868.

Spencer, R. W., and J. R. Christy, 1993: Precision lower stratospheric temperature monitoring with the MSU: Technique, validation, and results 1979-1991. J. Climate, 6, 1194-1204.

$\_,-$, and N. Grody, 1990: Global atmospheric temperature monitoring with satellite microwave measurements: Method and results 1979-84. J. Climate, 3, 1111-1128.

Stolarski, R., R. McPeters, G. Labow, S. Hollandsworth Frith, and L. Flynn, 2000: On the long-term calibration of the TOMS total ozone record. Proc. Quadrennial Ozone Symp., Sapporo, Japan, International Ozone Commission, 33-34.

Trenberth, K. E., and T. J. Hoar, 1997: El Niño and climate change. Geophys. Res. Lett., 24, 3057-3060.

World Meteorological Organization, 1999: Scientific Assessment of Ozone Depletion: 1998. WMO Rep. 44.

Zerefos, C. W., K. Tourpali, B. R. Bojkov, D. S. Balis, B. Rognerund, and I. S. A. Isaksen, 1997: Solar activity-total ozone relationships: Observations and model studies with heterogeneous chemistry. $J$. Geophys. Res., 102, 1561-1569. 